Journal of Computer Science 4 (10): 877-887, 2008

ISSN 1549-3636

(C) 2008 Science Publications

\title{
Topologies Induced by Relations with Applications
}

\author{
A.S. Salama \\ Department of Mathematics, Faculty of Science, Tanta University, Egypt
}

\begin{abstract}
Topological structures induced by relations represents the process of extracting interesting decision rules from data. The attributes reduction and the calculation of core are the essentials to extract the decision rules. Finding the reducts, core and decision rules topologically is a new mathematical tool for discovering attribute dependencies in information systems. Problem statement: These mathematical tools employ some concepts from topological spaces, relational databases, rough sets and information systems. The results using our approach are more accurate and applicable than that using the classical approaches such as in the father's approach of rough sets (Pawlak approach). Approach: Topologies generated using dominance (pre-order) relations and general binary relation are the knowledgebase of our approximations. We suggested a new algorithm (openness algorithm ) based on the topologies induced by general relations. Results: Results obtained by the proposed approach to find the reducts and core in terms of open and closed sets are compared with the existing method. Our proposed method is proved to be the accurate than results of any approaches using some types of binary relations such as order(pre-order) relations or symmetric relations. Conclusion: In this study, There are many approaches for obtaining topologies by relations and we used some of them in data reduction. These approaches were generalizations to Pawlak approaches namely, we ignored the notion of equivalence relations. Also, these approaches open the way for other approximations if we use the general topological recent concepts such as pre-open sets or semi-open sets.
\end{abstract}

Key words: Topological spaces, binary relations, relational databases, information system, rough sets, data reduction

\section{INTRODUCTION}

Topology is an important and interesting area of mathematics, the study of which will not only introduce you to new concepts and theorems but also put into context old ones like continuous functions. It is so fundamental that its influence is evident in almost every other branch of mathematics. This makes the study of topology relevant to all who aspire to be mathematicians whether their first love is algebra, analysis, category theory, chaos, continuum mechanics, dynamics, geometry, industrial mathematics, mathematical biology, mathematical economics, mathematical finance, mathematical modeling, mathematical physics, mathematics of communication, number theory, numerical mathematics, operation research or statistics. Topological notions like compactness, connectedness and denseness are as basic to mathematicians of today as sets and functions were to those of last century ${ }^{[3,8,9]}$.

For a long time, many individuals believed that abstract topological structures have limited application in the generalization of real line and complex plane or some connections to Algebra and other branches of mathematics. And it seems that there is a big gap between these structures and real life applications. We noticed that in some situations, the concept of relation is used to get topologies that are used in important applications such as computing topologies ${ }^{[15]}$, recombination spaces ${ }^{[2,7,16]}$ and information granulation which are used in biological sciences and some other fields of applications.

The aim of rough set theory is to give a description of the set of objects by logical, set-theoretical, topological etc. tools in terms of similarity relations and derived notions related by these relations. The description of the set of objects entails as well relationships and functional or near to functional dependencies among various similarity relations generated by various sets of the set of objects.

\section{MATERIALS AND METHODS}

Rough sets were first introduced by Pawlak ${ }^{[10,11]}$ and are based on approximation spaces. An approximation space is a pair $A=(O b, R)$. Here, $R$ is an equivalence relation, also called indiscernibility relation, imposing a granularity on the universe $\mathrm{Ob}$ such that $\mathrm{R} \subseteq \mathrm{Ob} \times \mathrm{Ob}$. 
Furthermore, we assume $\mathrm{Ob}$ to be finite. For $\mathrm{x} \in \mathrm{Ob}$, let $[x]_{R}$ be the equivalence class containing $x$, i.e., $[\mathrm{x}]_{\mathrm{R}}=\{\mathrm{y}: \mathrm{y} \mathrm{R} \mathrm{x}\}$.

Given an arbitrary set $\mathrm{X} \subseteq \mathrm{Ob}$, we wish to describe $\mathrm{X}$ in terms of elements or granules of Ob/R. Pawlak proposed the use of lower and upper approximations of a set $\mathrm{X}$, denoted $\underline{\mathrm{R}}(\mathrm{X})$ and $\overline{\mathrm{R}}(\mathrm{X})$, respectively. Lower and upper approximations are defined as:

$$
\begin{aligned}
& \underline{\mathrm{R}}(\mathrm{X})=\left\{\mathrm{x} \in \mathrm{Ob}:[\mathrm{x}]_{\mathrm{R}} \subseteq \mathrm{X}\right\} \\
& \overline{\mathrm{R}}(\mathrm{X})=\left\{\mathrm{x} \in \mathrm{Ob}:[\mathrm{x}]_{\mathrm{R}} \cap \mathrm{X} \neq \phi\right\}
\end{aligned}
$$

The semantics of the approximations of sets may be defined as follows:

- Elements of the universe that belong to $\underline{\mathrm{R}}(\mathrm{X})$ are those elements that surely belong to the set $\mathrm{X}$

- Elements that belong to $\overline{\mathrm{R}}(\mathrm{X})$ possibly belong to the set $\mathrm{X}$

- Elements that belong to $\mathrm{Ob} / \overline{\mathrm{R}}(\mathrm{X})$ are elements of the universe that surely do not belong to the set $\mathrm{X}$. Hence, the uncertainty lies in $\overline{\mathrm{R}}(\mathrm{X}) / \underline{\mathrm{R}}(\mathrm{X})$ which is also called area of uncertainty. Elements of the area of uncertainty may, or may not, belong to $\mathrm{X}$

The approximation operators can also be considered using membership functions. It is possible to define a rough membership function as presented in ${ }^{[12]}$.

Topologies induced by relations: Let $A=(\mathrm{Ob}, \mathrm{R})$ be an approximation space. The equivalence classes $\mathrm{Ob} \backslash \mathrm{R}$ of the relation $\mathrm{R}$ will be called elementary sets (atoms) in A. Every finite union of elementary sets in A will be called a composed set in A. The family of all composed sets in A will be denoted by com (A).

The family com (A) in the approximation space $\mathrm{A}=(\mathrm{Ob}, \mathrm{R})$ is a topology on the set $\mathrm{Ob}$.

Since the approximation space $A=(\mathrm{Ob}, \mathrm{R})$, defines uniquely the topological space $\tau(\mathrm{A})=(\mathrm{Ob}, \mathrm{com}$ (A)) and com (A) is the family of all open sets in $\tau$ (A) and $U / R$ is a basis for $\tau(A)$, then $\tau(A)$ is a quasidiscrete topology on $\mathrm{Ob}$ and com (A) is both the set of all open and closed sets in $\tau$ (A). Thus, the lower approximation and the upper approximation of any subset $\mathrm{X} \subseteq \mathrm{Ob}$ can be interpreted as the interior and the closure of the set $X$ in the topological space $\tau(A)$, respectively.

Lemma 1: If $\beta$ is a base for a topological space $(\mathrm{Ob}, \tau)$, where $\beta$ is a partition of $\mathrm{Ob}$, then for every subset $\mathrm{X} \subseteq \mathrm{Ob}$ : $\begin{array}{ll}\text { - } & \text { int }_{\tau}(X)=\bigcup\{B \in \beta: B \subseteq X\} \\ \text { - } & \operatorname{cl}_{\tau}(X)=\bigcup\{B \in \beta: B \cap X \neq \varphi\}\end{array}$

Proof: Only we prove (ii) because (i) is trivial. Let $\mathrm{x} \in \mathrm{cl}_{\tau}(\mathrm{X})$ then for every open set $\mathrm{G}$ containing $\mathrm{x}$, $\mathrm{X} \cap \mathrm{G} \neq \varphi$. But $\mathrm{G}=\bigcup_{\mathrm{B} \in \beta} \mathrm{B}$, then there exists $\mathrm{B}_{\mathrm{o}} \subseteq \mathrm{G}$ such that $\mathrm{x} \in \mathrm{B}_{\mathrm{o}} \subseteq \mathrm{G}$. But $\mathrm{B}_{\mathrm{o}}$ is an open set containing $\mathrm{x}$, hence $\mathrm{B}_{\mathrm{o}} \cap \mathrm{X} \neq \varphi$ and $\mathrm{x} \in \mathrm{U}\{\mathrm{B} \in \beta: \mathrm{B} \cap \mathrm{X} \neq \varphi\}$.

Conversely, if $x \in \bigcup\{B \in \beta: B \cap X \neq \varphi\}$ and $G$ is an open set containing $x$ and $\beta$ is a partition of $O b, x \in U$, then $x$ belongs to only one element of $\beta$ say $x \in B_{0}$. Then must $\mathrm{B}_{\mathrm{o}} \subseteq \mathrm{G}$, i.e., $\mathrm{x} \in \mathrm{B}_{\mathrm{o}} \subseteq \mathrm{G}$ but $\mathrm{B}_{\mathrm{o}} \cap \mathrm{X} \neq \varphi$, hence $\mathrm{G} \cap \mathrm{X} \neq \varphi$. Then $\mathrm{x} \in \mathrm{cl}_{\tau}(\mathrm{X})$.

Let $A_{1}=\left(\mathrm{Ob}, \mathrm{R}_{1}\right)$ and $\mathrm{A}_{2}=\left(\mathrm{Ob}, \mathrm{R}_{2}\right)$ be two approximation spaces. Then we say that the partition $\mathrm{Ob} / \mathrm{R}$ depends on the partition $\mathrm{Ob} / \mathrm{R}_{2}$ denoted $\mathrm{Ob} / \mathrm{R}_{1}$ if and only if $\mathrm{B}=\bigcup_{\mathrm{S} \in \mathrm{Ob} / \mathrm{R}_{2}} \mathrm{~S}, \forall \mathrm{B} \in \mathrm{Ob} / \mathrm{R}_{1}$.

Proposition 2: Let $\tau_{1}$ and $\tau_{2}$ be the topologies induced by the partitions $\mathrm{Ob} / \mathrm{R}_{1}$ and $\mathrm{Ob} / \mathrm{R}_{2}$ respectively. Then $\mathrm{Ob} / \mathrm{R}_{1} \leq \mathrm{Ob} / \mathrm{R}_{2}$ iff $\tau_{2} \subseteq \tau_{1}$.

Example: Consider the partitions $\beta_{1}=\left\{\left\{\mathrm{x}_{1}, \mathrm{x}_{2}\right\},\left\{\mathrm{x}_{3}\right\}\right.$, $\left.\left\{x_{4}\right\}\right\}$ and $\beta_{2}=\left\{\left\{x_{1}, x_{2}\right\},\left\{x_{3}, x_{4}\right\}\right\}$ of the set $O b=\left\{x_{1}\right.$, $\left.\mathrm{x}_{2}, \mathrm{x}_{3}, \mathrm{x}_{4}\right\}$. Then $\beta_{1} \leq \beta_{2}$ and $\tau_{2} \subseteq \tau_{1}$ where $\tau_{1}=\{\mathrm{Ob}, \phi$, $\left.\left\{x_{3}\right\},\left\{x_{4}\right\},\left\{x_{1,2}\right\},\left\{x_{3}, x_{4}\right\},\left\{x_{1}, x_{2} x_{3}\right\},\left\{x_{1}, x_{2} x_{4}\right\}\right\}$, $\tau_{2}=\left\{\mathrm{Ob}, \phi,\left\{\mathrm{x}_{1}, \mathrm{x}_{2}\right\},\left\{\mathrm{x}_{3}, \mathrm{x}_{4}\right\}\right\}$ are the topologies generated by $\beta_{1}$ and $\beta_{2}$ respectively.

For any topological space $(\mathrm{Ob}, \tau)$, we define the equivalence relation $\mathrm{E}(\tau)$ on the set $\mathrm{Ob}$ by $(\mathrm{x}, \mathrm{y}) \in \mathrm{E}(\tau)$ iff $\mathrm{cl}_{\tau}(\{\mathrm{x}\})=\mathrm{cl}_{\tau}(\{\mathrm{y}\}), \forall \mathrm{x}, \mathrm{y} \in \mathrm{Ob}$. The set of all equivalence classes of $\mathrm{E}(\tau)$ is denoted by $\mathrm{Ob} / \mathrm{E}(\tau)$.

Proposition 3: Let $\mathrm{A}=(\mathrm{Ob}, \mathrm{R})$ be an approximation space and let $\tau_{R}$ be the topology generated by the base $\mathrm{B}_{\mathrm{R}}=\mathrm{Ob} / \mathrm{R}$. If $(\mathrm{Ob}, \tau)$ is the quasi-discrete topological space has $\mathrm{Ob} / \mathrm{E}(\tau)$ as a base. Then $\tau_{\mathrm{R}}=\tau$ iff for all $\mathrm{x} \in \mathrm{B}_{\mathrm{R}} \in \beta_{\mathrm{R}}$ there exists $\mathrm{B} \in \mathrm{Ob} / \mathrm{E}(\tau)$ such that $\mathrm{x} \in \mathrm{B}$.

Lemma $4^{[15]}$ : For any topology $\tau$ on a set $\mathrm{Ob}$ and for all $\mathrm{x}, \mathrm{y} \in \mathrm{Ob}$, if $\mathrm{y} \in \mathrm{cl}_{\tau}(\{\mathrm{x}\})$ and $\mathrm{x} \in \mathrm{cl}_{\tau}(\{\mathrm{y}\})$ then $\mathrm{cl}_{\tau}(\{\mathrm{x}\})$ $=\mathrm{cl}_{\tau}(\{\mathrm{y}\})$.

Lemma $5^{[15]}$ : If $\tau$ is a quasi-discrete topology on a set $\mathrm{Ob}$, then $\mathrm{y} \in \mathrm{cl}_{\tau}(\{\mathrm{x}\})$ implies $\mathrm{x} \in \mathrm{cl}_{\tau}(\{\mathrm{y}\})$ for all $\mathrm{x}$, $\mathrm{y} \in \mathrm{Ob}$.

Lemma $6^{[15]}$ : If $\tau$ is a quasi-discrete topology on a set $\mathrm{Ob}$, then the family $\left\{\mathrm{cl}_{\tau}(\{\mathrm{x}\}): \mathrm{x} \in \mathrm{Ob}\right\}$ is a partition of $\mathrm{Ob}$. 
Proposition 7: Let $\tau$ be the topology induced by the partition $\beta_{\mathrm{R}}=\mathrm{Ob} / \mathrm{R}$. Then $\beta_{\mathrm{R}}=\mathrm{Ob} / \mathrm{E}(\tau)$.

Proof: $x \in B, B \in \beta_{R}$

- iff $\mathrm{x} \in \mathrm{cl}_{\tau}(\mathrm{B})=\bigcup_{\mathrm{y} \in \mathrm{B}} \mathrm{cl}_{\tau}(\{\mathrm{y}\})$

- iff $\mathrm{y}_{\mathrm{o}} \in \mathrm{B}$ and $\mathrm{x} \in \operatorname{cl}_{\tau}\left(\left\{\mathrm{y}_{\mathrm{o}}\right\}\right)$ iff $\operatorname{cl}_{\tau}(\{\mathrm{x}\})=\operatorname{cl}_{\tau}\left(\left\{\mathrm{y}_{\mathrm{o}}\right\}\right)$ (Lemma 2.2)

- $\quad$ iff $\left(x, y_{0}\right) \in E(\tau)$

- iff $\mathrm{A} \in \mathrm{Ob} / \mathrm{E}(\tau)$ such that $\mathrm{x} \in \mathrm{A}$

- iff $\beta_{\mathrm{R}}=\mathrm{Ob} / \mathrm{E}(\tau)$

For any $\mathrm{n}$ approximation spaces $\mathrm{A}_{1}=\left(\mathrm{Ob}, \mathrm{R}_{1}\right)$, $A_{2}=\left(O b, R_{2}\right), \ldots, A_{n}=\left(O b, R_{n}\right)$ we define the partition $\mathrm{Ob} / \mathrm{E}\left(\tau_{\text {ind }}\right)=\bigcap_{\mathrm{i}=1,2, \ldots, \mathrm{n}} \mathrm{Ob} / \mathrm{E}\left(\tau_{\mathrm{i}}\right)$.

Theorem 8: $\tau_{\mathrm{i}} \subseteq \tau_{\text {ind }}, \mathrm{i}=1,2, \ldots, \mathrm{n}$ where $\tau_{\mathrm{i}}$ and $\tau_{\text {ind }}$ are the topologies generated by the partitions $\mathrm{Ob} /\left(\tau_{\mathrm{i}}\right)$ and $\mathrm{Ob} / \mathrm{E}\left(\tau_{\text {ind }}\right)$ respectively.

Proof: Since $\mathrm{Ob} / \mathrm{E}\left(\tau_{\text {ind }}\right) \leq \mathrm{Ob} / \mathrm{E}\left(\tau_{\mathrm{i}}\right)$ for all $\mathrm{i}=1,2, \ldots, \mathrm{n}$ then $\tau_{\mathrm{I}} \subseteq \tau_{\text {ind }}$.

Example: Consider the topological space $(\mathrm{Ob}, \tau)$ where $\mathrm{Ob}=\left\{\mathrm{x}_{1}, \mathrm{x}_{2}, \mathrm{x}_{3}, \mathrm{x}_{4}\right\}$ and $\mathrm{b}=\left\{\left\{\mathrm{x}_{1}\right\},\left\{\mathrm{x}_{2}, \mathrm{x}_{3}\right\},\left\{\mathrm{x}_{4}\right\}\right\}$ is the base of $\tau$, then $\tau$ is a quasi-discrete topology and:

$$
\begin{aligned}
& \mathrm{cl}_{\tau}\left(\left\{\mathrm{x}_{1}\right\}\right)=\left\{\mathrm{x}_{1}\right\}, \mathrm{cl}_{\tau}\left(\left\{\mathrm{x}_{2}\right\}\right)=\left\{\mathrm{x}_{2}, \mathrm{x}_{3}\right\}, \mathrm{cl}_{\tau}\left(\left\{\mathrm{x}_{3}\right\}\right)=\left\{\mathrm{x}_{2}, \mathrm{x}_{3}\right\} \\
& \mathrm{cl}_{\tau}\left(\left\{\mathrm{x}_{4}\right\}\right)=\left\{\mathrm{x}_{4}\right\}
\end{aligned}
$$

Then $\mathrm{Ob} / \mathrm{E}(\tau)=\left\{\left\{\mathrm{x}_{1}\right\},\left\{\mathrm{x}_{2}, \mathrm{x}_{3}\right\},\left\{\mathrm{x}_{4}\right\}\right\}=\beta$.

Example: Consider the approximation spaces $A_{1}=\left(O b, R_{1}\right), \quad A_{2}=\left(O b, R_{2}\right)$ and $A_{3}=\left(O b, R_{3}\right)$ where $\mathrm{Ob}=\left\{\mathrm{x}_{1}, \mathrm{x}_{2}, \mathrm{x}_{3}, \mathrm{x}_{4}\right\}$ and $\mathrm{Ob} / \mathrm{E}\left(\tau_{1}\right)=\left\{\left\{\mathrm{x}_{1}\right\}, \quad\left\{\mathrm{x}_{2}, \mathrm{x}_{3}\right\}\right.$,

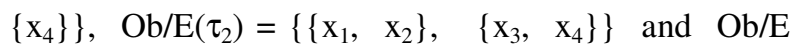
$\left(\tau_{3}\right)=\left\{\left\{x_{1}\right\},\left\{x_{2}\right\},\left\{x_{3}, x_{4}\right\}\right\}$ are the bases of $\tau_{1}, \tau_{2}$ and $\tau_{3}$ respectively, then $\mathrm{Ob} / \mathrm{E}\left(\tau_{\text {ind }}\right)=\left(\mathrm{Ob} / \mathrm{E}\left(\tau_{1}\right)\right) \cap\left(\mathrm{Ob} / \mathrm{E}\left(\tau_{2}\right)\right)$ $\cap\left(\mathrm{Ob} / \mathrm{E}\left(\tau_{3}\right)\right)=\left\{\left\{\mathrm{x}_{1}\right\},\left\{\mathrm{x}_{2}\right\},\left\{\mathrm{x}_{3}\right\},\left\{\mathrm{x}_{4}\right\}\right\}$ is the partition induced by $\mathrm{E}\left(\tau_{\text {ind }}\right)$. Then $\tau_{\mathrm{l}} \subset \tau_{\text {ind }}, \mathrm{i}=1,2,3$.

Topologies generated using similarity relations: A similar relation $\mathrm{R}$ on $\mathrm{Ob}$ is any relation satisfies:

- For any $\mathrm{x} \in \mathrm{Ob}, \mathrm{xRx} \quad$ (reflexive)

- For any $\mathrm{x}, \mathrm{y} \in \mathrm{Ob}$, if $\mathrm{xRy}$ then $\mathrm{yRx}$ (Symmetric)

For $\mathrm{x} \in \mathrm{Ob}$, we define the similar class containing $\mathrm{x}$ by $R(x)=\{y \in O b: x R y\}$.
The relation $\mathrm{R}$ on $\mathrm{Ob}$ defined by $\mathrm{xRy}$ iff $\mathrm{d}(\mathrm{x}, \mathrm{y})<\mathrm{n}$ where $(\mathrm{Ob}, \mathrm{d})$ is a metric space with a metric function $\mathrm{d}$ defined as: $\mathrm{d}(\mathrm{x}, \mathrm{y})=|\mathrm{x}-\mathrm{y}|$ and $\mathrm{n}=\operatorname{card}(\mathrm{Ob})$, is a similar relation.

Proposition 9 For any similar relation $\mathrm{R}$ defined on $\mathrm{Ob}$ we have:

- $x \in R(x)$

- $y \in R(x)$ iff $x \in R(y)$

- $\quad x R y$ iff $x \in R(y)$ and $y \in R(x)$

The class $\beta=\{B(x): x \in X\}$ is called a symmetric covering of a set $X$ if $x \in B(y)$ iff $y \in B(x)$. Then the class $\beta=\{R(x): x \in O b\}$ is a symmetric covering of the set of objects $\mathrm{Ob}$.

Let $\beta$ is the symmetric covering of $\mathrm{Ob}$ by the similar relation $R$. Then we define a relation $R_{\beta}$ induced by $\beta$ by $x R_{\beta} y$ iff there exist $B \in \beta$ and $x, y \in B$.

Proposition 10: The relation $\mathrm{R}_{\beta}$ is a similar relation on the set of objects $\mathrm{Ob}$.

Since $\beta$ is a covering of $O b$, then for any $x \in O b$ there exists $B \in \beta$ such that $x \in B$ hence $x, x \in B \in \beta$ then $x R_{\beta}$. Let $x R_{\beta} y$ then there exists $B \in \beta$ such that $x, y \in B$ then $y, x \in B$ hence $y R_{\beta} x$.

Proposition 10 for every $\mathrm{x} \in \mathrm{Ob}$ we have:

$$
R_{\beta}(x)=\bigcup_{B \in \beta(x)} B \text {, where } \beta(x)=\{B \in \beta: x \in B\}
$$

\section{Proof:}

$$
\begin{aligned}
\mathrm{y} \in \mathrm{R}_{\beta}(\mathrm{x}) & \Leftrightarrow \exists \mathrm{B} \in \beta \text { and } \mathrm{x}, \mathrm{y} \in \mathrm{B} \\
& \Leftrightarrow \exists \mathrm{B} \in \beta \text { and } \mathrm{x} \in \mathrm{B} \text { and } \mathrm{y} \in \mathrm{B} \\
& \Leftrightarrow \exists \mathrm{B} \in \beta \text { and } \mathrm{y} \in \mathrm{B} \\
& \Leftrightarrow \bigcup_{\mathrm{B} \in \beta(\mathrm{x})} \mathrm{B}
\end{aligned}
$$

Let $\beta$ is the covering of $\mathrm{Ob}$. Then we define the class $\beta *=\left\{R_{\beta}(x): x \in O b\right\}$.

Proposition 11: The class $\beta^{*}$ is a symmetric covering of the set of objects $\mathrm{Ob}$ and $\mathrm{R}_{\beta} \subseteq \mathrm{R}_{\beta^{*} \text {. }}$

\section{Proof:}

- $x \in R \beta(y) \Leftrightarrow \exists B \in \beta(y)$ and $x \in B \Leftrightarrow \exists B \in \beta(x)$ and $\mathrm{y} \in \mathrm{B} \Leftrightarrow \mathrm{y} \in \mathrm{R} \beta(\mathrm{x})$

- $\quad$ Let $(x, y) \in R_{\beta} \Rightarrow \exists B \in \beta$ and $x, y \in B$

$\Rightarrow \mathrm{B} \in \beta(\mathrm{x})$ and $\mathrm{B} \in \beta(\mathrm{y})$

$\Rightarrow \mathrm{B} \in \beta(\mathrm{x}) \cap \beta(\mathrm{y})$ 


$$
\begin{aligned}
& \Rightarrow \mathrm{B} \in \bigcup_{\mathrm{B} \in \beta(\mathrm{x})} \mathrm{B}=\mathrm{R}_{\beta}(\mathrm{x}) \in \beta^{*} \\
& \Rightarrow \mathrm{x}, \mathrm{y} \in \mathrm{B} \in \beta^{*} \\
& \Rightarrow \mathrm{x}, \mathrm{y} \in \mathrm{R}_{\beta^{*}}
\end{aligned}
$$

Let $\mathrm{A} \subseteq \mathrm{Ob}$ be any non empty subset of the set of objects. Then $\mathrm{A}$ is called a similar pre-class of $\mathrm{R}$ if for any $\mathrm{x}, \mathrm{y} \in \mathrm{A} \Rightarrow(\mathrm{x}, \mathrm{y}) \in \mathrm{R}$.

Proposition 12 Every similar class $\mathrm{R}(\mathrm{x})$ is a maximal similar pre-class.

For an element $\mathrm{x} \in \mathrm{Ob}$ we define a class called the pre-similar class of $\mathrm{x}$ as follows:

$\mathrm{L}_{\mathrm{R}}(\mathrm{x})=\{\mathrm{A} \subseteq \mathrm{Ob}: \mathrm{x} \in \mathrm{A}$ and $\mathrm{A}$ is similar pre-class of $\mathrm{R}\}$. Let $L_{R}=\left\{L_{R}(x): x \in O b\right\}$ be the family of all pre-similar classes. Then we define a relation $R^{*}$ on $L_{R}$ by for any $\mathrm{L}_{\mathrm{R}}(\mathrm{x}), \quad \mathrm{L}_{\mathrm{R}}(\mathrm{y}) \in \mathrm{L}_{\mathrm{R}}, \mathrm{L}_{\mathrm{R}}(\mathrm{x}) \mathrm{R} * \mathrm{~L}_{\mathrm{R}}(\mathrm{y})$ iff there exist $\mathrm{A} \in \mathrm{L}_{\mathrm{R}}(\mathrm{x})$ and $\mathrm{B} \in \mathrm{L}_{\mathrm{R}}(\mathrm{y})$ and $\mathrm{A} \cap \mathrm{B} \neq \varphi$.

\section{Proposition 13:}

- The relation $\mathrm{R}^{*}$ on $\mathrm{L}_{\mathrm{R}}$ is a similar relation

- $\quad x R y$ iff $L_{R}(x) R * L_{R}(y)$ for any $x, y \in O b$

\section{Proof:}

- Since for any $L_{R}(x) \in L_{R}$ and $A \in L_{R}(x), A \cap A \neq \phi$ then $L_{R}(x) R^{*} L_{R}(x)$ hence $R^{*}$ is reflexive. Also if $\mathrm{L}_{\mathrm{R}}(\mathrm{x}) \mathrm{R} * \mathrm{~L}_{\mathrm{R}}(\mathrm{y})$ then there exist $\mathrm{A} \in \mathrm{L}_{\mathrm{R}}(\mathrm{x})$ and $\mathrm{B} \in \mathrm{L}_{\mathrm{R}}(\mathrm{y})$ such that $\mathrm{A} \cap \mathrm{B} \neq \phi$, hence $\mathrm{B} \cap \mathrm{A} \neq \phi$, hence $L_{R}(y) R * L_{R}(x)$. Then $R *$ is symmetric

- Firstly, we will prove that $x R y \Rightarrow L_{R}(x) R * L_{R}(y)$

Let $(x, y) \in R \Rightarrow\{x, y\}$ is a similar pre-class of $R$. $\Rightarrow$ there exist a similar class $\mathrm{R}(\mathrm{x})$ such that $\{\mathrm{x}, \mathrm{y}\} \subseteq$ $\mathrm{R}(\mathrm{x})$ and $\mathrm{R}(\mathrm{x}) \in \mathrm{L}_{\mathrm{R}}(\mathrm{x})$ but $\mathrm{R}$ is symmetric then $\mathrm{R}(\mathrm{x}) \in \mathrm{L}_{\mathrm{R}}(\mathrm{y})$, then there exist $\mathrm{A}=\mathrm{R}(\mathrm{x}) \in \mathrm{L}_{\mathrm{R}}(\mathrm{x})$ and $\mathrm{B}=\mathrm{R}(\mathrm{x}) \in \mathrm{L}_{\mathrm{R}}(\mathrm{y})$ and $\mathrm{A} \cap \mathrm{B} \neq \varphi$, hence $\mathrm{L}_{\mathrm{R}}(\mathrm{x}) \mathrm{R} * \mathrm{~L}_{\mathrm{R}}(\mathrm{y})$.

Conversely, let for some $x, y \in O b, L_{R}(x) R * L_{R}(y)$ then there exist $R(z) \in L_{R}(x)$ and $R(z) \in L_{R}(y)$ a similar class of $R$. hence $x \in R(z)$ and $y \in R(z)$ then $x, y \in R(z)$ hence $x$ Ry.

Let $L_{R}(x)$ be the pre-similar class of $x \in O b$. Then we define a set $\mathrm{L}_{\mathrm{R}}^{*}(\mathrm{x})=\bigcup_{\mathrm{A} \in \mathrm{L}_{\mathrm{R}}(x)}$ A called the R-link of $\mathrm{x}$, where $A \in L_{R}(x)$ and $A \neq R(x)$.

If $L_{R}^{*}(x)=O b$ then it is called open $R$ - link of $x$ and if $\mathrm{L}_{\mathrm{R}}^{*}(\mathrm{x}) \subset \mathrm{Ob}$ then it is called closed $\mathrm{R}$ - link of $\mathrm{x}$.

The class $M=\left\{L^{*}(x): x \in O b\right\}$ of all $R$ - links of $\mathrm{x} \in \mathrm{Ob}$ is a subbase of a topology on $\mathrm{Ob}$ called the linked topology and denoted $\tau_{\mathrm{L}_{\mathrm{R}}^{*}}$.

\section{Proposition 14:}

- For any $\mathrm{x} \in \mathrm{Ob}, \mathrm{L}_{\mathrm{R}}{ }(\mathrm{x}) \subseteq \mathrm{R}(\mathrm{x})$

- The class $\mathrm{M}$ is a symmetric covering of $\mathrm{Ob}$

\section{Proof:}

- Let $y \in L * R(x) \Rightarrow y \in \underset{A \in L_{R}(x)}{\cup} A \Rightarrow$ there exists $\mathrm{A}=\mathrm{R}(\mathrm{x}) \in \mathrm{LR}(\mathrm{x})$ and $\mathrm{y} \in \mathrm{A}$ then $\mathrm{y} \in \mathrm{R}(\mathrm{x}) \Rightarrow \mathrm{L} * \mathrm{R}(\mathrm{x})$ $\subseteq \mathrm{R}(\mathrm{x})$

- For any $\mathrm{x} \in \mathrm{Ob}, \mathrm{x} \in \mathrm{L}_{\mathrm{R}}^{*}(\mathrm{y}) \Rightarrow \mathrm{M}$ is covering of $\mathrm{Ob}$

Now let $x \in L_{R}^{*}(y) \Rightarrow x \in \bigcup_{A \in L_{R}(x)} A$ :

- there exist $A=R(x) \in L_{R}(y)$ and $x \in R(x)$

- $x, y \in R(x)$

- $y \in \mathrm{L}_{\mathrm{R}}^{*}(\mathrm{x})$

then $\mathrm{M}$ is a symmetric covering of $\mathrm{Ob}$.

\section{Proposition 15:}

- The linked topology $\tau_{L^{*} R_{R}}$ is finer than the similar topology $\tau_{R}$, where $\tau_{R}$ is the topology generated by the subbase $\{R(x): x \in O b\}$

- $\quad \mathrm{xRy} \Rightarrow \exists$ open set $\mathrm{u} \in \tau_{\mathrm{L}^{*} \mathrm{R}}$ and $\mathrm{x}, \mathrm{y} \in \mathrm{u}$

Example: Let $\mathrm{Ob}=\left\{\mathrm{c}_{1}, \mathrm{c}_{2}, \ldots, \mathrm{c}_{7}\right\}$ be the set of objects which is seven computers in a local network in a certain company. Let $\tau$ be the irregular topology on the set of objects which induced by a general relation on $\mathrm{Ob}$ which makes the following graph. We define a similar relation $\mathrm{R}$ on the set of objects by: Two computers $\mathrm{x}$ and $y$ are in relation by $\mathrm{R}$ iff the computer $\mathrm{x}$ has a copy of a certain program in the computer $\mathrm{y}$.

Then we can define the similar classes of $\mathrm{R}$ as follows:

- $\mathrm{R}\left(\mathrm{c}_{1}\right)=\left\{\mathrm{c}_{1}, \mathrm{c}_{2}, \mathrm{c}_{4}\right\}, \mathrm{R}\left(\mathrm{c}_{2}\right)=\left\{\mathrm{c}_{1}, \mathrm{c}_{2}, \mathrm{c}_{3}, \mathrm{c}_{4}, \mathrm{c}_{5}\right\}, \mathrm{R}\left(\mathrm{c}_{3}\right)$ $=\left\{c_{2}, c_{3}, c_{5}\right\}, R\left(c_{4}\right)=\left\{c_{1}, c_{2}, c_{5}, c_{6}, c_{4}\right\}, R\left(c_{5}\right)=\left\{c_{2}\right.$, $\left.\mathrm{c}_{3}, \mathrm{c}_{4}, \mathrm{c}_{6}, \mathrm{c}_{5}\right\}, \mathrm{R}\left(\mathrm{c}_{6}\right)=\left\{\mathrm{c}_{4}, \mathrm{c}_{5}, \mathrm{c}_{6}, \mathrm{c}_{7}\right\}, \mathrm{R}\left(\mathrm{c}_{7}\right)=\left\{\mathrm{c}_{6}\right.$, $\left.\mathrm{c}_{7}\right\}$. Then we have $\mathrm{L}_{\mathrm{R}}\left(\mathrm{c}_{1}\right)=\left\{\left\{\mathrm{c}_{1}\right\},\left\{\mathrm{c}_{1}, \mathrm{c}_{2}\right\},\left\{\mathrm{c}_{1}, \mathrm{c}_{4}\right\}\right.$, $\left.\left\{\mathrm{c}_{1}, \mathrm{c}_{2}, \mathrm{c}_{4}\right\}\right\}, \mathrm{L}_{\mathrm{R}}\left(\mathrm{c}_{2}\right)=\left\{\left\{\mathrm{c}_{2}\right\},\left\{\mathrm{c}_{2}, \mathrm{c}_{1}\right\},\left\{\mathrm{c}_{2}, \mathrm{c}_{4}\right\},\left\{\mathrm{c}_{2}\right.\right.$, $\left.\mathrm{c}_{5}\right\},\left\{\mathrm{c}_{2}, \mathrm{c}_{3}\right\},\left\{\mathrm{c}_{2}, \mathrm{c}_{3}, \mathrm{c}_{5}\right\},\left\{\mathrm{c}_{2}, \mathrm{c}_{1}, \mathrm{c}_{4}\right\},\left\{\mathrm{c}_{2}, \mathrm{c}_{4}, \mathrm{c}_{5}\right\}$, $\left.\left\{\mathrm{c}_{2}, \mathrm{c}_{1}, \mathrm{c}_{3}, \mathrm{c}_{4}, \mathrm{c}_{5}\right\}\right\}, \mathrm{L}_{\mathrm{R}}\left(\mathrm{c}_{3}\right)=\left\{\left\{\mathrm{c}_{3}\right\},\left\{\mathrm{c}_{3}, \mathrm{c}_{2}\right\},\left\{\mathrm{c}_{3}\right.\right.$, $\left.\left.\mathrm{c}_{5}\right\},\left\{\mathrm{c}_{3}, \mathrm{c}_{2}, \mathrm{c}_{5}\right\}\right\}, \mathrm{L}_{\mathrm{R}}\left(\mathrm{c}_{4}\right)=\left\{\left\{\mathrm{c}_{4},\left\{\mathrm{c}_{4}, \mathrm{c}_{1}\right\},\left\{\mathrm{c}_{4}, \mathrm{c}_{2}\right\}\right.\right.$, $\left\{\mathrm{c}_{4}, \mathrm{c}_{5}\right\},\left\{\mathrm{c}_{4}, \mathrm{c}_{6}\right\},\left\{\mathrm{c}_{4}, \mathrm{c}_{1}, \mathrm{c}_{2}\right\},\left\{\mathrm{c}_{4}, \mathrm{c}_{2}, \mathrm{c}_{5}\right\},\left\{\mathrm{c}_{4}, \mathrm{c}_{5}\right.$, $\left.\left.\mathrm{c}_{6}\right\},\left\{\mathrm{c}_{4}, \mathrm{c}_{1}, \mathrm{c}_{2}, \mathrm{c}_{5}, \mathrm{c}_{6}\right\}\right\}, \mathrm{L}_{\mathrm{R}}\left(\mathrm{c}_{5}\right)=\left\{\left\{\mathrm{c}_{5}\right\},\left\{\mathrm{c}_{5}, \mathrm{c}_{2}\right\}\right.$, $\left\{\mathrm{c}_{5}, \mathrm{c}_{4}\right\},\left\{\mathrm{c}_{5}, \mathrm{c}_{3}\right\},\left\{\mathrm{c}_{5}, \mathrm{c}_{6}\right\},\left\{\mathrm{c}_{5}, \mathrm{c}_{2}, \mathrm{c}_{3}\right\},\left\{\mathrm{c}_{5}, \mathrm{c}_{2}, \mathrm{c}_{4}\right\}$, $\left.\left\{\mathrm{c}_{5}, \mathrm{c}_{4}, \mathrm{c}_{6}\right\},\left\{\mathrm{c}_{2}, \mathrm{c}_{5}, \mathrm{c}_{4}, \mathrm{c}_{5}, \mathrm{c}_{6}\right\}\right\}, \mathrm{L}_{\mathrm{R}}\left(\mathrm{c}_{6}\right)=\left\{\left\{\mathrm{c}_{6}\right\},\left\{\mathrm{c}_{6}\right.\right.$, 
$\left.\mathrm{c}_{4}\right\},\left\{\mathrm{c}_{6}, \mathrm{c}_{5}\right\},\left\{\mathrm{c}_{6}, \mathrm{c}_{7}\right\},\left\{\mathrm{c}_{6}, \mathrm{c}_{4}, \mathrm{c}_{7}\right\},\left\{\mathrm{c}_{6}, \mathrm{c}_{5}, \mathrm{c}_{7}\right\},\left\{\mathrm{c}_{6}\right.$, $\left.\left.\mathrm{c}_{4}, \mathrm{c}_{5}\right\},\left\{\mathrm{c}_{4}, \mathrm{c}_{5}, \mathrm{c}_{6}, \mathrm{c}_{7}\right\}\right\}$

- $\mathrm{L}_{\mathrm{R}}\left(\mathrm{c}_{7}\right)=\left\{\left\{\mathrm{c}_{7}\right\}, \quad\left\{\mathrm{c}_{6}, \mathrm{c}_{7}\right\}\right\}$. Also, we have: $\mathrm{L}_{\mathrm{R}}\left(\mathrm{c}_{1}\right)=\left\{\mathrm{c}_{1}, \mathrm{c}_{2}, \mathrm{c}_{4}\right\}, \mathrm{L} *_{\mathrm{R}}\left(\mathrm{c}_{2}\right)=\left\{\mathrm{c}_{1}, \mathrm{c}_{2}, \mathrm{c}_{3}, \mathrm{c}_{4}, \mathrm{c}_{5}\right\}$, $\mathrm{L}^{*}{ }_{\mathrm{R}}\left(\mathrm{c}_{3}\right)=\left\{\mathrm{c}_{2}, \mathrm{c}_{3}, \mathrm{c}_{5}\right\} \mathrm{L}_{\mathrm{R}}\left(\mathrm{c}_{4}\right)=\left\{\mathrm{c}_{1}, \mathrm{c}_{2}, \mathrm{c}_{5}, \mathrm{c}_{6}, \mathrm{c}_{4}\right\}$, $\mathrm{L}_{\mathrm{R}}\left(\mathrm{c}_{5}\right)=\left\{\mathrm{c}_{2}, \mathrm{c}_{3}, \mathrm{c}_{4}, \mathrm{c}_{5}, \mathrm{c}_{6}\right\}, \mathrm{L}_{\mathrm{R}}\left(\mathrm{c}_{6}\right)=\left\{\mathrm{c}_{4}, \mathrm{c}_{5}, \mathrm{c}_{6}\right.$, $\left.\mathrm{c}_{7}\right\}, \mathrm{L} *_{\mathrm{R}}\left(\mathrm{c}_{7}\right)=\left\{\mathrm{c}_{7}\right\}$

Then the linked topology $\tau_{\mathrm{L}_{\mathrm{R}}}$ is finer than the similar topology, such that $\mathrm{L}^{*}{ }_{\mathrm{R}}\left(\mathrm{c}_{\mathrm{i}}\right) \subseteq \mathrm{R}\left(\mathrm{c}_{\mathrm{i}}\right)$ for all $\mathrm{i}=1,2, \ldots, 7$.

For any subset $A$ of the set of objects, we define two sets $\underline{R}(\mathrm{~A})$ and $\overline{\mathrm{R}}(\mathrm{A})$, they are called the lower and upper similar classes of $\mathrm{A}$ by:

$$
\underline{\mathrm{R}}(\mathrm{A})=\bigcup\{\mathrm{R}(x): \mathrm{R}(\mathrm{x}) \subseteq \mathrm{A}\}
$$

and

$$
\overline{\mathrm{R}}(\mathrm{A})=\bigcup\{\mathrm{R}(x): \mathrm{R}(x) \cap \mathrm{A} \neq \varphi\}
$$

Let $\underline{\tau}_{\mathrm{R}}$ be the topology induced by the subbase $\{\underline{R}(\mathrm{~A}): \mathrm{A} \subseteq \mathrm{Ob}\}$ this topology called the lower similar topology. Also we define the topology $\bar{\tau}_{\mathrm{R}}$ which is called the upper similar topology and generated by the subbase $\{\overline{\mathrm{R}}(\mathrm{A}): \mathrm{A} \subseteq \mathrm{Ob}\}$.

Proposition 16: Let $\underline{\tau}_{\mathrm{R}}$ and $\bar{\tau}_{\mathrm{R}}$ be the lower and upper similar topologies then:

- $\quad \bar{\tau}_{\mathrm{R}} \subseteq \underline{\tau}_{\mathrm{R}}$ if $\mathrm{R}$ is an equivalence relation

- $\quad \bar{\tau}_{\mathrm{R}} \subseteq \underline{\tau}_{\mathrm{R}}$ if $\mathrm{R}$ is a similar relation

- $\underline{\tau}_{\mathrm{R}}$ and $\bar{\tau}_{\mathrm{R}}$ are in general not comparable if $\mathrm{R}$ is a general relation

The following proposition present another way to generate topologies from similarity relations.

Proposition 17: $\tau^{* *}{ }_{\mathrm{R}}=\{\mathrm{A} \subseteq \mathrm{Ob}: \forall x \in \mathrm{A}, \mathrm{R}(x) \subseteq \mathrm{A}\}$ is a topology on $\mathrm{Ob}$.

\section{Proof:}

- $\mathrm{Ob}, \varphi \in \tau^{* *}{ }_{\mathrm{R}}$ is clearly

- If $\mathrm{A}_{1}, \mathrm{~A}_{2}, \ldots \in \tau_{\mathrm{R}}^{* *}$ and $\mathrm{x} \in \bigcup_{\mathrm{i}} \mathrm{A}_{\mathrm{i}}$ for some $\mathrm{i}_{\text {。 }}$ then $\mathrm{R}(\mathrm{x}) \subseteq \mathrm{A}_{\mathrm{i}_{\mathrm{o}}}$ then $\mathrm{R}(x) \subseteq \bigcup_{\mathrm{i}} \mathrm{A}_{\mathrm{i}}$ hence $\bigcup_{\mathrm{i}} \mathrm{A}_{\mathrm{i}} \in \tau^{* *}{ }_{\mathrm{R}}$

- Let $\mathrm{A}_{1}, \mathrm{~A}_{2} \in \tau_{\mathrm{R}}^{* *}$, then $\forall x \in \mathrm{A}_{1} \cap \mathrm{A}_{2}$ we have $\mathrm{R}(\mathrm{x}) \subseteq \mathrm{A}_{1}$ and $\mathrm{R}(\mathrm{x}) \subseteq \mathrm{A}_{2}$ hence $\mathrm{R}(\mathrm{x}) \subseteq \mathrm{A}_{1} \cap \mathrm{A}_{2}$ then $A_{1} \cap A_{2} \in \tau^{* *}{ }_{R}$
Example: Consider $\mathrm{Ob}=\{\mathrm{a}, \mathrm{b}, \mathrm{c}, \mathrm{d}\}$ be the set of objects with a similar relation $\mathrm{R}$ its similar classes are:

- $\quad \mathrm{R}(\mathrm{a})=\{\mathrm{a}, \mathrm{c}\}, \mathrm{R}(\mathrm{b})=\{\mathrm{b}, \mathrm{d}\}, \mathrm{R}(\mathrm{c})=\{\mathrm{a}, \mathrm{c}, \mathrm{d}\}$ and $R(d)=\{b, c, d\}$. Then: $\tau_{R}=\{O b, \varphi\{c\},\{d\},\{c$, $d\},\{a, c\},\{b, d\},\{a, c, d\},\{b, c, d\}\}, \bar{\tau}_{R}=\{O b, \varphi$, $\{\mathrm{d}, \mathrm{c}\},\{\mathrm{a}, \mathrm{c}, \mathrm{d}\},\{\mathrm{b}, \mathrm{c}, \mathrm{d}\}\}$ and $\tau^{* *} \mathrm{R}=\{\mathrm{Ob}, \varphi\}$ then $\tau^{* *} \mathrm{R} \subset \bar{\tau}_{\mathrm{R}} \subset \underline{\tau}_{\mathrm{R}}$

- The conjugate relation $\bar{R}$ of $\mathrm{R}$ is defined by (x,y) $\in \overline{\mathrm{R}}$ iff $(\mathrm{x}, \mathrm{y}) \notin \mathrm{R}$ or $\mathrm{x}=\mathrm{y}$

\section{Proposition 18:}

- $\quad \underline{\mathrm{R}} \cap \overline{\mathrm{R}}=\mathrm{I}, \mathrm{I}$ is the identity relation

- $\overline{\mathrm{R}}$ is a similar relation

- $\overline{\overline{\mathrm{R}}}=\mathrm{R}$

\section{Proof:}

- $\quad(x, y) \in R \cap \bar{R}$ iff $x=y \Rightarrow R \cap \bar{R}=I$

- $(x, x) \in \bar{R}$ such that $x=x$ and if $(x, y) \in \bar{R}$ then $(\mathrm{x}, \mathrm{y}) \notin \mathrm{R}$ or $\mathrm{x}=\mathrm{y}$ then $(\mathrm{y}, \mathrm{x}) \notin \mathrm{R}$ or $\mathrm{y}=\mathrm{x}$ hence $(\mathrm{y}, \mathrm{x}) \in \overline{\mathrm{R}}$

- $\quad(\mathrm{x}, \mathrm{y}) \in \overline{\overline{\mathrm{R}}} \Leftrightarrow(\mathrm{x}, \mathrm{y}) \notin \overline{\mathrm{R}}$ or $\mathrm{x}=\mathrm{y} \Leftrightarrow(\mathrm{x}, \mathrm{y}) \in \mathrm{R}$ or $\mathrm{x}=\mathrm{y} \Leftrightarrow(\mathrm{x}, \mathrm{y}) \in \mathrm{R}$

Example: Let $\mathrm{Ob}=\{\mathrm{a}, \mathrm{b}, \mathrm{c}, \mathrm{d}\}$ be the set of objects with the similar relation $R=\{(a, a),(b, b),(c, c),(d, d)$, $(d, c),(c, d),(d, b),(b, d),(c, b),(b, c),(b, a),(a, b)\}$. Then $\overline{\mathrm{R}}=\mathrm{I} \cup(\mathrm{Ob} \times \mathrm{Ob}-\mathrm{R})=\{(\mathrm{a}, \mathrm{a}),(\mathrm{b}, \mathrm{b}), \quad(\mathrm{c}),,(\mathrm{d}, \mathrm{d})$, $(\mathrm{c}, \mathrm{a}),(\mathrm{a}, \mathrm{c}),(\mathrm{d}, \mathrm{a}),(\mathrm{a}, \mathrm{d})\}$.

Topologies generated using dominance (pre-order) relations: For a long time, many mathematicians believed that there is a large deviation between abstract topological structures and computing ${ }^{[12-14]}$.

A relation $\mathrm{R}$ on a set $\mathrm{Ob}$ is called a dominance relation (pre-order) whenever $\mathrm{R}$ is both reflexive and transitive. If $x$ is related to $y$, we write $x R y$ and say that $x$ dominances $y$. The set $R(y)=\{x: y R x\}$ is called the before set.

Example: Let $\mathrm{Ob}=\{1,2,3,4,5,6\}$ and $(\mathrm{x}, \mathrm{y}) \in \mathrm{R}$ if and only if $\mathrm{x} \mid \mathrm{y}, \mathrm{x}, \mathrm{y}, \in \mathrm{Ob}$.

$\mathrm{R}=\{(1,1),(1,2),(1,3),(1,4),(1,5),(4,4),(5$, $5),(6,6),(1,6),(2,2),(2,4),(2,6),(3,3),(3,6)\}$. The relation $\mathrm{R}$ is a dominance relation.

In a finite space $(\mathrm{Ob}, \tau)$, it is clear that $\tau^{\mathrm{c}}=\{\mathrm{Ob}-\mathrm{G}: \mathrm{G} \in \tau\}$ is also a topology. 
A subset $F \subset X$ is a closed set iff $F=\bigcup_{y \in F} F y$ such that $F y=\{x: y R x\}$ (Fy is the smallest closed set about $x)$. This is the dual of our representation of open sets.

If $\mathrm{R}$ is a dominance relation on a set $\mathrm{Ob}$, then its dual $R_{D}$ is defined by the requirement $y R_{D} x$ if and only if $\mathrm{xR} y$.

A point $x$ in a subset $U$ of $\mathrm{Ob}$ is insulated from $\mathrm{Ob}-\mathrm{U}$ if and only if there is no point $\mathrm{y}$ in $\mathrm{Ob}-\mathrm{U}$ such that $\mathrm{y}$ dominates $\mathrm{x}$.

Lemma 19: Let $R$ be a dominance relation on a set $\mathrm{Ob}, \mathrm{U} \subset \mathrm{Ob}, \mathrm{P} \in \mathrm{U}$ the following are equivalent $\mathrm{s}$ :

- $\quad \mathrm{P}$ is insulated from $\mathrm{Ob}-\mathrm{U}$

- $P \in U,(y, P) \in R$, then $y \in U$

Proof: First, consider $\mathrm{p} \in \mathrm{U}$ is insulated from $\mathrm{Ob}-\mathrm{U}$, (y, p) $\in R$. Let $y \notin U$, then $y \in O b-U$, So $(y, p) \notin R$, but $(y$, p) $\in R$, a contradiction, then $y \in U$.

Second, consider $\mathrm{p} \in \mathrm{U}, \mathrm{x} \in \mathrm{Ob}-\mathrm{U}$, suppose $(\mathrm{x}, \mathrm{p})$ $\in R$. Then $x \in U$ contradicts that $x \notin U$, then $\tau_{R}=\{U$ $\subset \mathrm{Ob}: \mathrm{x}$ is insulated from $\mathrm{Ob}-\mathrm{U}, \forall \mathrm{x} \in \mathrm{U}\}(\mathrm{x}, \mathrm{p}) \notin \mathrm{R}$.

Proposition 20: If $\mathrm{R}$ is a dominance relation on a set $\mathrm{Ob}$, then is topology on $\mathrm{Ob}$.

Proof: Clearly $\mathrm{Ob}$ and $\phi$ are elements in $\tau_{\mathrm{R}}$ let $\mathrm{U}_{\mathrm{i}} \in \tau_{\mathrm{R}}$ for every $i \in I$. For any $x \in \bigcup_{i \in I} U_{i}$ and $(y, x) \in R$, there is $\mathrm{i}_{0} \in \mathrm{I}$ such that $\mathrm{x} \in \mathrm{U}_{\mathrm{i}_{0}}$. By openness of $U_{\mathrm{i}_{0}}$, we have $\mathrm{y} \in \mathrm{U}_{\mathrm{i}_{0}} \subset \bigcup_{\mathrm{i}=\mathrm{I}} \mathrm{U}_{\mathrm{i}}$. Therefore $\bigcup_{\mathrm{i} \in \mathrm{I}} \mathrm{U}_{\mathrm{i}} \in \tau_{\mathrm{R}}$. Also, if $\mathrm{A}$ and $\mathrm{B}$ are elements of $\tau_{R}$, then $\tau^{-2}=\{O b, \varphi,\{d\}\}$.

According to the above proposition we give the following algorithm to check the openness of a subset $\mathrm{U} \subset \mathrm{Ob}$ with respect to a dominance relation $\mathrm{R}$.

\section{Openness algorithm:}

i- $\quad$ Find Ob-U

ii- Investigates the existence of any pair $(a, b)$ $\in \mathrm{R}, \mathrm{a} \in \mathrm{Ob}-\mathrm{U}, \mathrm{b} \in \mathrm{U}$, we have two cases:

- If there exists such pair, then $U$ is not open

- If there is not such pair (a, b), then $U$ is open

The following example (Table 1) is an application for the above algorithm.
Table 1: Application for Openness algorithm

\begin{tabular}{lll}
\hline $\mathrm{P}(\mathrm{Ob})$ & Insulated points & Open sets \\
\hline$\{1\}$ & $\sqrt{ }$ & $\sqrt{ }$ \\
$\{2\}$ & & \\
$\{3\}$ & & \\
$\{4\}$ & $\sqrt{ }$ & $\sqrt{ }$ \\
$\{1,2\}$ & & \\
$\{1,3\}$ & & \\
$\{1,4\}$ & & \\
$\{2,3\}$ & & \\
$\{2,4\}$ & $\sqrt{ }$ \\
$\{3,4\}$ & & \\
$\{1,2,3\}$ & & $\sqrt{ }$ \\
$\{1,2,4\}$ & & $\sqrt{ }$ \\
$\{2,3,4\}$ & $\sqrt{ }$ & \\
$\{1,3,4\}$ & $\sqrt{ }$ & \\
Ob & & \\
\hline
\end{tabular}

Then the induced topology is $\tau_{R}=\{\mathrm{Ob}, \varphi,\{1\},\{1$, $2\},\{1,2,3\}\}$.

Let $\mathrm{Ob}$ be the set of objects and let $\mathrm{R}$ be any binary relation on $\mathrm{Ob}$. The relation $\mathrm{R}$ gives rise to a closure operator $\mathrm{cl}_{\mathrm{R}}$ as follows:

$\left.\operatorname{cl}_{R}(A)=A \bigcup\{y \in X\} \mid \exists x \in A:(y, x) \in R\right\}$ for every $A \subseteq O b$

Lemma 21: The interior operator corresponding to $\mathrm{cl}_{\mathrm{R}}$ is given by:

$$
\operatorname{int}_{\mathrm{R}}(\mathrm{A})=\left\{\mathrm{y} \in \mathrm{A}: \forall \mathrm{x} \in \mathrm{A}^{\mathrm{c}}, \sim \mathrm{yRx}\right\}
$$

Proof: $\operatorname{int}_{R}(A)=\left[\operatorname{cl}_{R}\left(A^{c}\right)\right]^{c}$

$=\left\{A c \cup\left\{y \in X: \exists x \in A^{c},(y, x) \in R\right\}\right\}^{c}$

$=A \cap\left\{y \in X: \exists x \in A^{c},(y, x) \in\right\}^{c}$

$=\mathrm{A} \cap\left\{\mathrm{y} \in \mathrm{X}: \forall \mathrm{x} \in \mathrm{A}^{\mathrm{c}},(\mathrm{y}, \mathrm{x}) \notin \mathrm{R}\right\}^{\mathrm{c}}$

$=\left\{\mathrm{y} \in \mathrm{A}: \forall \mathrm{x} \in \mathrm{A}^{\mathrm{c}}, \sim \mathrm{yRx}\right\}$

Thus the interior operator of A consist of those elements of $\mathrm{A}$ which are not R-related to any elements outside A.

Lemma 22: For any relation $\mathrm{R}$ on $\mathrm{Ob},\left(\mathrm{Ob}, \mathrm{cl}_{\mathrm{R}}\right)$ is closure space.

In the following we will give an example (Table 2) for closure space generated by a general relation.

Example: Consider $\mathrm{Ob}\{\mathrm{a}, \mathrm{b}, \mathrm{c}\}$ and $\mathrm{R}$ is a binary relation on $\mathrm{Ob}, \mathrm{R}=\{(\mathrm{a}, \mathrm{b}),(\mathrm{c}, \mathrm{b}),(\mathrm{a}, \mathrm{c})\}$. Then we have the Table 2 for closures and interiors of the subsets of Ob: We note from Table 2 that:

- $\operatorname{cl}_{\mathrm{R}}(\phi)=\phi$

- $\mathrm{A} \subseteq \mathrm{cl}_{\mathrm{R}}(\mathrm{A})$

- $\operatorname{cl}_{R}(A \cup B)=\operatorname{cl}_{R}(A) \cup \operatorname{cl}_{R}(B)$ for all $A, B \subseteq O b$ 
Table 2: Closure space generated by a general relation

\begin{tabular}{lll}
\hline $\mathrm{A}$ & $\mathrm{Cl}_{\mathrm{R}}(\mathrm{A})$ & $\operatorname{int}_{\mathrm{r}}(\mathrm{A})$ \\
\hline$\{\mathrm{a}\}$ & $\{\mathrm{a}\}$ & $\phi$ \\
$\{\mathrm{b}\}$ & $\{\mathrm{b}, \mathrm{c}\}$ & $\{\mathrm{b}\}$ \\
$\{\mathrm{c}\}$ & $\{\mathrm{a}, \mathrm{c}\}$ & $\phi$ \\
$\{\mathrm{a}, \mathrm{b}\}$ & $\mathrm{Ob}$ & $\{\mathrm{b}\}$ \\
$\{\mathrm{a}, \mathrm{c}\}$ & $\{\mathrm{a}, \mathrm{c}\}$ & $\phi$ \\
$\{\mathrm{b}, \mathrm{c}\}$ & $\mathrm{Ob}$ & $\{\mathrm{b}, \mathrm{c}\}$ \\
$\mathrm{Ob}$ & $\mathrm{Ob}$ & $\mathrm{Ob}$ \\
$\phi$ & $\phi$ & $\phi$ \\
\hline
\end{tabular}

Table 3: Closures and interiors of the subsets of $\mathrm{Ob}$

\begin{tabular}{lll}
\hline $\mathrm{A}$ & $\mathrm{Cl}_{\mathrm{R}}(\mathrm{A})$ & $\operatorname{int}_{\mathrm{R}}(\mathrm{A})$ \\
\hline$\{1\}$ & $\{1\}$ & $\{1\}$ \\
$\{2\}$ & $\{2,3\}$ & $\phi$ \\
$\{3\}$ & $\{2,3\}$ & $\phi$ \\
$\{1,2\}$ & $\mathrm{Ob}$ & $\{1\}$ \\
$\{1,3\}$ & $\mathrm{Ob}$ & $\{1\}$ \\
$\{2,3\}$ & $\{2,3\}$ & $\{2,3\}$ \\
$\mathrm{Ob}$ & $\mathrm{Ob}$ & $\mathrm{Ob}$ \\
$\phi$ & $\phi$ & $\phi$ \\
\hline
\end{tabular}

Lemma 23 If $\mathrm{Ob}$ be non-empty set and $\mathrm{R}$ is transitive relation, then $\left(\mathrm{x}, \mathrm{cl}_{\mathrm{R}}\right)$ is topological space.

Example: Consider the relation $\mathrm{R}=\{(1,1),(2,3),(3$, $2),(2,2)\}$ on $\mathrm{Ob}=\{1,2,3\}$. Table 3 shows closures and interiors of the subsets of $\mathrm{Ob}$.

From Table 3, we have:

- $\operatorname{clR}(\phi)=\phi$

- $A \subseteq \mathrm{cl}_{\mathrm{R}}(\mathrm{A}$

- $\operatorname{cl}_{\mathrm{R}}(\mathrm{A} \cup \mathrm{B})=\mathrm{cl}_{\mathrm{R}}(\mathrm{A}) \cup \mathrm{cl}_{\mathrm{R}}(\mathrm{B})$ for all $\mathrm{A}, \mathrm{B} \subseteq \mathrm{Ob}$

- $\operatorname{cl}_{\mathrm{R}}\left(\mathrm{cl}_{\mathrm{R}}(\mathrm{A})\right)=\mathrm{cl}_{\mathrm{R}}(\mathrm{A})$ for all $\mathrm{A} \subseteq \mathrm{Ob}$

Topologies generated using general binary relations: The basic aim of this section is to generate topological structures using the lower and the upper approximations of any binary relation. Given general approximation space $\mathrm{A}=(\mathrm{Ob}, \mathrm{R})$ where $\mathrm{R}$ here is any general binary relation on $\mathrm{Ob}$. For any subset $\mathrm{X}$ of $\mathrm{Ob}$ we define lower and upper approximations as follows:

$$
\mathrm{R}(\mathrm{X})=\{\mathrm{x} \in \mathrm{Ob}: \forall \mathrm{y}((\mathrm{x}, \mathrm{y}) \in \mathrm{R} \Rightarrow \mathrm{y} \in \mathrm{X})\}
$$

and

$$
\mathrm{R}(\mathrm{X})=\{\mathrm{x} \in \mathrm{Ob}: \exists \mathrm{y}((\mathrm{x}, \mathrm{y}) \in \mathrm{R} \wedge \mathrm{y} \in \mathrm{X})\}
$$

Then the following structures are topologies on $\mathrm{Ob}$ :

$$
\begin{aligned}
& \underset{-1}{\tau}=\{\mathrm{G} \subseteq \mathrm{Ob}: \underset{-}{\mathrm{R}}(\mathrm{G})=\mathrm{G}\} \\
& \tau_{-2}=\left\{\mathrm{G} \subseteq \mathrm{Ob}:{\underset{-}{\mathrm{R}}}^{2}(\mathrm{G})=\underset{-}{\mathrm{R}}(\underset{-}{\mathrm{R}}(\mathrm{G}))=\mathrm{G}\right\} \\
& \underset{-3}{\tau}=\left\{\mathrm{G} \subseteq \mathrm{Ob}:{\underset{-}{\mathrm{R}}}^{3}(\mathrm{G})=\underset{-}{\mathrm{R}}\left(\underset{-}{\mathrm{R}}\left(\mathrm{R}_{-}(\mathrm{G})\right)\right)=\mathrm{G}\right\} \ldots . \\
& \tau_{-\mathrm{n}-1}=\left\{\mathrm{G} \subseteq \mathrm{Ob}: \mathrm{R}_{-}^{\mathrm{n}-1}(\mathrm{G})=\mathrm{G}, \mathrm{n}=|\mathrm{Ob}|\right\}
\end{aligned}
$$

These topologies have the property that: $\tau_{-1} \subseteq$ $\tau_{-2} \subseteq \cdots \subseteq \tau_{-\mathrm{n}-1}$

Also, if we deal with the upper approximation instead of the lower approximation we can construct the following topologies:

$$
\begin{aligned}
& \bar{\tau}_{1}=\{\mathrm{G} \subseteq \mathrm{Ob}: \overline{\mathrm{R}}(\mathrm{G})=\mathrm{G} \vee \overline{\mathrm{R}}(\mathrm{G})=\varphi\} \\
& \bar{\tau}_{2}=\left\{\mathrm{G} \subseteq \mathrm{Ob}: \overline{\mathrm{R}}^{2}(\mathrm{G})=\overline{\mathrm{R}}(\overline{\mathrm{R}}(\mathrm{G}))=\mathrm{G} \vee \overline{\mathrm{R}}(\overline{\mathrm{R}}(\mathrm{G}))=\phi\right\} \\
& \bar{\tau}_{3}=\left\{\mathrm{G} \subseteq \mathrm{Ob}: \overline{\mathrm{R}}^{-3}(\mathrm{G})=\overline{\mathrm{R}}(\overline{\mathrm{R}}(\overline{\mathrm{R}}(\mathrm{G})))=\mathrm{G} \vee \overline{\mathrm{R}}(\overline{\mathrm{R}}(\overline{\mathrm{R}}(\mathrm{G})))=\phi\right\} \ldots \ldots . \\
& \bar{\tau}_{\mathrm{n}-1}=\left\{\mathrm{G} \subseteq \mathrm{Ob}: \overline{\mathrm{R}}^{\mathrm{n}-1}(\mathrm{G})=\mathrm{G} \vee \mathrm{R}^{\mathrm{n}-1}(\mathrm{G})=\phi, \mathrm{n}=|\mathrm{Ob}|\right\}
\end{aligned}
$$

These topologies have the property that $\bar{\tau}_{1} \subseteq \bar{\tau}_{2} \subseteq \ldots \subseteq \bar{\tau}_{\mathrm{n}-1}$.

In the following we will give some illustrative examples and remarks.

Example: Let $\mathrm{Ob}=\{\mathrm{a}, \mathrm{b}, \mathrm{c}, \mathrm{d}\}$ be the universe and let $\mathrm{R}=\{(\mathrm{a}, \mathrm{b}),(\mathrm{c}, \mathrm{d}),(\mathrm{b}, \mathrm{d}),(\mathrm{d}, \mathrm{a}),(\mathrm{c}, \mathrm{b})\}$ be a general binary relation on $\mathrm{Ob}$. Then we have the following topologies on $\mathrm{Ob}$ using the lower approximation:

$$
\begin{aligned}
& \tau=\{\mathrm{Ob}, \varphi,\{\mathrm{a}, \mathrm{b}, \mathrm{d}\}\} \\
& {\underset{-2}{\tau}}_{-2}=\{\mathrm{Ob}, \varphi,\{\mathrm{a}, \mathrm{b}, \mathrm{d}\}\} \\
& {\underset{-3}{\tau}}_{-3}=\{\mathrm{Ob}, \phi,\{\mathrm{a}\},\{\mathrm{b}\},\{\mathrm{d}\},\{\mathrm{a}, \mathrm{b}\},\{\mathrm{a}, \mathrm{d}\},\{\mathrm{b}, \mathrm{d}\},\{\mathrm{a}, \mathrm{b}, \mathrm{d}\}\}
\end{aligned}
$$

If we made more iteration to introduce more topologies using the lower approximation we will obtain that: $\tau_{-4}=\tau_{-1}, \tau_{-5}=\tau_{-2}$ and $\tau_{-6}=\tau_{-3}$ and so on.

Also we have the following topologies on $\mathrm{Ob}$ using the upper approximation:

$$
\begin{aligned}
& \overline{\tau_{1}}=\{\mathrm{Ob}, \varphi,\{\mathrm{c}\}\} \\
& \overline{\tau_{2}}=\{\mathrm{Ob}, \varphi,\{\mathrm{c}\}\} \\
& \overline{\tau_{3}}=\{\mathrm{Ob}, \phi,\{\mathrm{d}\},\{\mathrm{c}\},\{\mathrm{a}, \mathrm{c}\},\{\mathrm{b}, \mathrm{c}\},\{\mathrm{a}, \mathrm{b}, \mathrm{c}\},\{\mathrm{a}, \mathrm{c}, \mathrm{d}\},\{\mathrm{b}, \mathrm{c}, \mathrm{d}\}\}
\end{aligned}
$$

If we made more iteration to introduce more topologies using the upper approximation we will obtain that: $\bar{\tau}_{4}=\bar{\tau}_{1}, \bar{\tau}_{5}=\bar{\tau}_{2}$ and $\bar{\tau}_{6}=\bar{\tau}_{3}$ and so on.

Remark: If the relation $\mathrm{R}$ on the universe $\mathrm{Ob}$ is constant, then all topologies induced by the lower or the upper approximations are indiscrete.

If the relation $\mathrm{R}$ on the universe $\mathrm{Ob}$ is identity or contain the identity relation, then all topologies induced by the lower or the upper approximations are discrete. 
If we made more iteration to introduce more topologies using the lower approximation or the upper approximation, then all new iterations will introduce the same topologies we before obtained.

Another method for constructing topologies using the lower and the upper approximations is presented bellow:

All the following are topologies on $\mathrm{Ob}$ :

$$
\begin{aligned}
& \bar{\tau}_{-}^{-1}=\{\underline{R}(\mathrm{G}): \underset{-}{\mathrm{R}}(\mathrm{G})=\overline{\mathrm{R}}(\mathrm{G})\} \\
& \bar{\tau}^{-2}=\left\{\mathrm{R}^{2}(\mathrm{G}): \mathrm{R}^{2}(\mathrm{G})=\mathrm{R}^{-2}(\mathrm{G})\right\} \\
& \bar{\tau}^{3}=\left\{\mathrm{R}^{3}(\mathrm{G}): \mathrm{R}^{3}(\mathrm{G})=\overline{\mathrm{R}}^{3}(\mathrm{G})\right\} \\
& \ldots . ., \tau^{-\mathrm{n}-1}=\left\{\underline{R}^{\mathrm{n}-1}(\mathrm{G}): \underline{-}^{\mathrm{n}-1}(\mathrm{G})=\mathrm{R}^{-\mathrm{n}-1}(\mathrm{G})\right\}
\end{aligned}
$$

Also, all the following structures are topologies on Ob. $\quad \tau^{1}=\{\mathrm{R}(\overline{\mathrm{R}}(\mathrm{G})): \mathrm{R}(\overline{\mathrm{R}}(\mathrm{G}))=\overline{\mathrm{R}}(\mathrm{R}(\mathrm{G}))\}, \quad \tau^{2}=\{\overline{\mathrm{R}}(\overline{\mathrm{R}}$ $(\mathrm{R}(\mathrm{G}))): \mathrm{R}(\overline{\mathrm{R}}(\mathrm{R}(\mathrm{G})))=\overline{\mathrm{R}}(\mathrm{R}(\overline{\mathrm{R}}(\mathrm{G})))\}$ and so on.

Example: According to Example we have:

$$
\begin{aligned}
& \bar{\tau}^{-1}=\{\mathrm{Ob}, \varphi,\{\mathrm{d}\},\{\mathrm{a}, \mathrm{b}, \mathrm{c}\}\} \\
& \bar{\tau}^{2}=\{\mathrm{Ob}, \varphi,\{\mathrm{d}\}\} \\
& \overline{-}^{3} \\
& \underline{-}^{3}=\{\mathrm{Ob}, \varphi,\{\mathrm{d}\}\}
\end{aligned}
$$

\section{RESULTS}

The basic aim of our paper is to generate topological structures that are used to generate many topological measures and then using it in data reduction. First, we are used general binary relation to generate topological structures using the lower and the upper approximations. Make use of these methods we succeeded to introduce many topologies such as lower topologies from degree 1 to degree $\mathrm{n}$ where $\mathrm{n}$ is any order. Also, the topologies from degree 1 to $\mathrm{n}$ using upper approximations. Second, we are used the approach of closure operator and interior operator to induced topological structures.

We govern the importance of these topologies by the specified properties of relations that it are generate. Lemmas, propositions and theorems are mentioned to filter these topology to know which topology is used in applications of data reduction.
Table 4: The information system

\begin{tabular}{lllll}
\hline $\mathrm{Ob}$ & $\mathrm{a} 1$ & $\mathrm{a} 2$ & $\mathrm{a} 3$ & $\mathrm{a} 4$ \\
\hline $\mathrm{x}_{1}$ & 1 & 2 & 9 & 6 \\
$\mathrm{x}_{2}$ & 3 & 2 & 6 & 2 \\
$\mathrm{x}_{3}$ & 3 & 6 & 3 & 3 \\
$\mathrm{x}_{4}$ & 4 & 2 & 2 & 3 \\
$\mathrm{x}_{5}$ & 6 & 6 & 5 & 4 \\
\hline
\end{tabular}

In our application example we succeeded to obtain reducts of multi-valued (set-valued) datasets that handled differently using ROSETTA software and proved that our solution is more accurate than solution in $^{[10,14]}$.

Now if $\tau_{\mathrm{I}_{\mathrm{At}}}$ is the topology induced by $\left\{\operatorname{Int}_{\mathrm{At}}(\mathrm{X}): \mathrm{X} \subseteq \mathrm{Ob}\right\}\left(\tau_{\mathrm{C}_{\mathrm{At}}}\right.$ or $\tau_{\mathrm{N}_{\mathrm{At}}}$ can be used alternately),

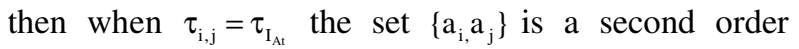
reduct of At in S. On the other hand, if $\tau_{\mathrm{i}, \mathrm{j}} \neq \tau_{\mathrm{I}_{\mathrm{At}}}$ for all $\mathrm{i}$, $\mathrm{j}=1,2, \ldots, \mathrm{n}$ we must calculate the highest topologies $\tau_{1,2,3}, \ldots, \tau_{\mathrm{n}-2, \mathrm{n}-1, \mathrm{n}}$ and the subset $\left\{\mathrm{a}_{\mathrm{i}}, \mathrm{a}_{\mathrm{j}}, \mathrm{a}_{\mathrm{k}}\right\}$ is a third order reduct of At in $S$ when $\tau_{i, j, k}=\tau_{I_{\Lambda T}}$. By the same manner, we can define a highly order reducts of At in $\mathrm{S}$.

In each case, the topological core of At in $\mathrm{S}$ is the intersection of all reducts (intersection of all the same order reducts). This core called the interior core and

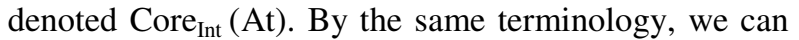
define the closure core $\left(\right.$ Core $_{\mathrm{Cl}}$ (At)) and the neighborhood core $\left(\operatorname{Core}_{\mathrm{N}}(\mathrm{At})\right)$.

Illustrated Example Consider the information system shown by Table 4 and if we choose $r=2$, then $N_{a_{i}}(x, r)=\left\{y \in O b:\left|f_{a_{i}}(x)-f_{a_{i}}(y)\right| \leq 2\right\}$, hence we have the following subbases:

$\zeta_{1}=\left\{\left\{x_{1}, x_{2}, x_{3}\right\},\left\{x_{1}, x_{2}, x_{3}, x_{4}\right\},\left\{x_{2}, x_{3}, x_{4}, x_{5}\right\},\left\{x_{4}\right.\right.$, $\left.\left.\mathrm{x}_{5}\right\}\right\}$

$\zeta_{2}=\left\{\left\{\mathrm{x}_{1}, \mathrm{x}_{2}, \mathrm{x}_{4}\right\},\left\{\mathrm{x}_{3}, \mathrm{x}_{5}\right\}\right\}$

$\varsigma_{3}=\left\{\left\{x_{1}\right\},\left\{x_{3}, x_{4}, x_{5}\right\},\left\{x_{2}, x_{5}\right\},\left\{x_{3}, x_{4}\right\},\left\{x_{2}, x_{3}, x_{5}\right\}\right\}$

$\varsigma_{4}=\left\{\left\{x_{2}, x_{3}, x_{4}, x_{5}\right\},\left\{x_{1}, x_{5}\right\}, O b\right\}$

The corresponding bases are:

$\beta_{1}=\left\{\left\{x_{1}, x_{2}, x_{3}\right\},\left\{x_{1}, x_{2}, x_{3}, x_{4}\right\},\left\{x_{2}, x_{3}, x_{4}, x_{5}\right\},\left\{x_{4}\right.\right.$, $\left.\left.\left.\mathrm{x}_{5}\right\}\right\},\left\{\mathrm{x}_{4}\right\},\left\{\mathrm{x}_{2}, \mathrm{x}_{3}\right\},\left\{\mathrm{x}_{2}, \mathrm{x}_{3}, \mathrm{x}_{4}\right\}\right\}$

$\beta_{2}=\left\{\left\{x_{1}, x_{2}, x_{4}\right\},\left\{x_{3}, x_{5}\right\}\right\}$

$\beta_{3}=\left\{\left\{x_{1}\right\},\left\{x_{3}, x_{4}, x_{5}\right\},\left\{x_{2}, x_{5}\right\},\left\{x_{3}, x_{4}\right\},\left\{x_{2}, x_{3}, x_{5}\right\}\right.$, $\left.\left\{x_{5}\right\},\left\{x_{3}\right\},\left\{x_{3}, x_{5}\right\}\right\}$

$\beta_{4}=\left\{\left\{x_{2}, x_{3}, x_{4}, x_{5}\right\},\left\{x_{1}, x_{5}\right\},\left\{x_{5}\right\}, O b\right\}$

The corresponding topologies are:

$\tau_{1}=\left\{\mathrm{Ob}, \varphi,\left\{\mathrm{x}_{1}, \mathrm{x}_{2}, \mathrm{x}_{3}\right\},\left\{\mathrm{x}_{1}, \mathrm{x}_{2}, \mathrm{x}_{3}, \mathrm{x}_{4}\right\},\left\{\mathrm{x}_{2}, \mathrm{x}_{3}, \mathrm{x}_{4}, \mathrm{x}_{5}\right\}\right.$, $\left.\left\{\mathrm{x}_{4}, \mathrm{x}_{5}\right\},\left\{\mathrm{x}_{4}\right\},\left\{\mathrm{x}_{2}, \mathrm{x}_{3}\right\},\left\{\mathrm{x}_{2}, \mathrm{x}_{3}, \mathrm{x}_{4}\right\}\right\}$

$\tau_{2}=\left\{\mathrm{Ob}, \varphi,\left\{\mathrm{x}_{1}, \mathrm{x}_{2}, \mathrm{x}_{4}\right\},\left\{\mathrm{x}_{3}, \mathrm{x}_{5}\right\}\right\}$ 
$\tau_{3}=\left\{\mathrm{Ob}, \varphi,\left\{\mathrm{x}_{1}\right\},\left\{\mathrm{x}_{3}, \mathrm{x}_{4}, \mathrm{x}_{5}\right\},\left\{\mathrm{x}_{2}, \mathrm{x}_{5}\right\},\left\{\mathrm{x}_{3}, \mathrm{x}_{4}\right\},\left\{\mathrm{x}_{2}\right.\right.$, $\left.\mathrm{x}_{3}, \mathrm{x}_{5}\right\},\left\{\mathrm{x}_{5}\right\},\left\{\mathrm{x}_{3}\right\},\left\{\mathrm{x}_{3}, \mathrm{x}_{5}\right\},\left\{\mathrm{x}_{1}, \mathrm{x}_{2}, \mathrm{x}_{5}\right\},\left\{\mathrm{x}_{1}, \mathrm{x}_{3}, \mathrm{x}_{4}\right.$, $\left.\mathrm{x}_{5}\right\},\left\{\mathrm{x}_{1}, \mathrm{x}_{2}, \mathrm{x}_{3}, \mathrm{x}_{5}\right\},\left\{\mathrm{x}_{1}, \mathrm{x}_{3}, \mathrm{x}_{4}\right\},\left\{\mathrm{x}_{1}, \mathrm{x}_{5}\right\},\left\{\mathrm{x}_{1}, \mathrm{x}_{3}\right.$, $\left.\mathrm{x}_{5}\right\},\left\{\mathrm{x}_{1}, \mathrm{x}_{3}\right\},\left\{\mathrm{x}_{2}, \mathrm{x}_{3}, \mathrm{x}_{4}, \mathrm{x}_{5}\right\},\left\{\mathrm{x}_{2}, \mathrm{x}_{3}, \mathrm{x}_{5}\right\},\left\{\mathrm{x}_{3}, \mathrm{x}_{4}\right.$, $\left.\left.\mathrm{x}_{5}\right\}\right\}$

$\tau_{4}=\left\{\mathrm{Ob}, \varphi,\left\{\mathrm{x}_{2}, \mathrm{x}_{3}, \mathrm{x}_{4}, \mathrm{x}_{5}\right\},\left\{\mathrm{x}_{1}, \mathrm{x}_{5}\right\},\left\{\mathrm{x}_{5}\right\}\right\}$

If we considered the set of all attributes then $\tau_{\mathrm{N}_{\mathrm{At}}}$ is the discrete topology, but the second order topologies are given such that: $\tau_{1,2} \neq \tau_{\mathrm{N}_{\mathrm{At}}}, \tau_{1,3}=\tau_{\mathrm{N}_{\mathrm{At}}}, \tau_{1,4} \neq \tau_{\mathrm{N}_{\mathrm{At}}}$, $\tau_{2,3}=\tau_{\mathrm{N}_{\mathrm{At}}}, \tau_{2,4} \neq \tau_{\mathrm{N}_{\mathrm{At}}}, \tau_{3,4} \neq \tau_{\mathrm{N}_{\mathrm{At}}}$ Then $\left\{\mathrm{a}_{1}, \mathrm{a}_{3}\right\}$ and $\left\{\mathrm{a}_{2}\right.$, $\left.\mathrm{a}_{3}\right\}$ are second order reducts of At and the second order core is given by $\operatorname{Core}_{\mathrm{N}}(\mathrm{At})=\left\{\mathrm{a}_{3}\right\}$.

\section{DISCUSSION}

In this section, we briefly describe the main idea of our work using the rheumatic fever datasets. No doubt that, the rheumatic fever is a very common disease. It has many symptoms differs from patient to another but though the diagnosis it is the same. So, we obtained the following data on seven rheumatic fever patients from Banha fever hospital, Egypt. All patients are between 912 years old with history of Arthurian began from age 3-5 years. This disease has many symptoms and it is usually started in young age and still with the patient along his life. Table 5 introduced the seven patients characterized by 8 symptoms (Attributes) using them to decide the diagnosis for each patient (Decision Attribute). Table 6 shows the rheumatic fever information system.

Table 5: Rheumatic fever data

\begin{tabular}{lll}
\hline Attribute name & Attribute values & Attribute refers to \\
\hline Sex (S) & $\mathrm{S}_{1}$ & Male \\
& $\mathrm{S}_{2}$ & Female \\
Pharyngitis (P) & yes & Yes \\
& no & No \\
Arthritis (A) & $\mathrm{a}_{0}$ & No arthritis \\
& $\mathrm{a}_{1}$ & Began in the knee \\
& $\mathrm{a}_{2}$ & Began in the ankle \\
Carditis (C) & $\mathrm{r}_{1}$ & Affected \\
& $\mathrm{r}_{2}$ & Not affected \\
Chorea (Ch) & yes & Yes \\
& no & No \\
ESR & $\mathrm{e}_{1}$ & Normal \\
& $\mathrm{e}_{2}$ & High \\
Abdonominal pain (Ap) & $\mathrm{p}_{1}$ & Absent \\
& $\mathrm{p}_{2}$ & Present \\
Headache (H) & yes & Yes \\
& no & No \\
Diagnosis (D) & $\mathrm{d}_{1}$ & Rheumatic arthritis \\
& $\mathrm{d}_{2}$ & Rheumatic carditis \\
& $\mathrm{d}_{3}$ & Rheumatic arthritis \\
& & and carditis \\
\hline
\end{tabular}

Let us consider the topological space $\tau_{\mathrm{a}}$ generated using binary relation defined on the attribute a. Also, using the same terminology the topological space $\tau_{\mathrm{B}}$ is the topology generated using general relation defined on a subset of attributes B of all condition attributes At. The decision attribute generates the topology $\tau_{\mathrm{D}}$.

Now, we will use the following suggestion, The set of attributes $\mathrm{B} \subseteq$ At is called a reduct if $\tau_{\mathrm{B}} \leq \tau_{\mathrm{D}}$ and $\mathrm{B}$ is minimal, where:

$$
\left(\tau_{\mathrm{B}} \leq \tau_{\mathrm{D}} \text { iff } \forall \mathrm{G} \in \tau_{\mathrm{B}}, \exists \mathrm{G}^{\prime} \in \tau_{\mathrm{D}} \text { s.t. } \mathrm{G} \subset \mathrm{G}^{\prime}, \mathrm{G}, \mathrm{G}^{\prime} \neq \mathrm{U}\right)
$$

The attribute $a \in A t$ is called the core if $\left|\tau_{\mathrm{a}}\right| \succ\left|\tau_{\mathrm{b}}\right|, \forall \mathrm{a}, \mathrm{b} \in \mathrm{At}, \mathrm{b} \neq \mathrm{a}$.

When the classical technique of rough set theory (ROSETTA software) ${ }^{[4,5,13]}$ used to obtain reducts and core of our data we found that we have 8 reducts of Table 6 with out any intersections among them. So, we do not have any core of Table 6 . The set of obtained reducts is as follows:

$$
\begin{aligned}
& R e d(A t)=\{\{S \vee C \vee C h\},\{S \vee A \vee C\}, \\
& \{S \vee P \vee A \vee A p\},\{P \vee A \vee C \vee C \vee A p\}, \\
& \{C \vee E S R\},\{P \vee A \vee E S R \vee A p\}, \\
& \{A \vee C \vee H\},\{P \vee A \vee A p \vee H\}\}
\end{aligned}
$$

Now, after getting the reducts of Table 6 using the ROSETTA software. We will convert Table 5-8 using Table 7.

Now we will apply the above contributions on Table 7 where $\mathrm{Ob}=\left\{\mathrm{x}_{1}, \mathrm{x}_{2}, \mathrm{x}_{3}, \mathrm{x}_{4}, \mathrm{x}_{5}, \mathrm{x}_{6}, \mathrm{x}_{7}\right\}$ is the set of objects, the set of condition attributes is $A t=\{\alpha, \beta, \delta\}$ and the decision attribute is the diagnosis D.

According to the binary relation $\mathrm{R}_{\mathrm{B}}=\left\{(\mathrm{x}, \mathrm{y}), \mathrm{f}_{\mathrm{B}}(\mathrm{x})^{\mathrm{c}} \subseteq \mathrm{f}_{\mathrm{B}}(\mathrm{y}), \mathrm{B} \subseteq \mathrm{At}\right\}$ we can construct the following topologies:

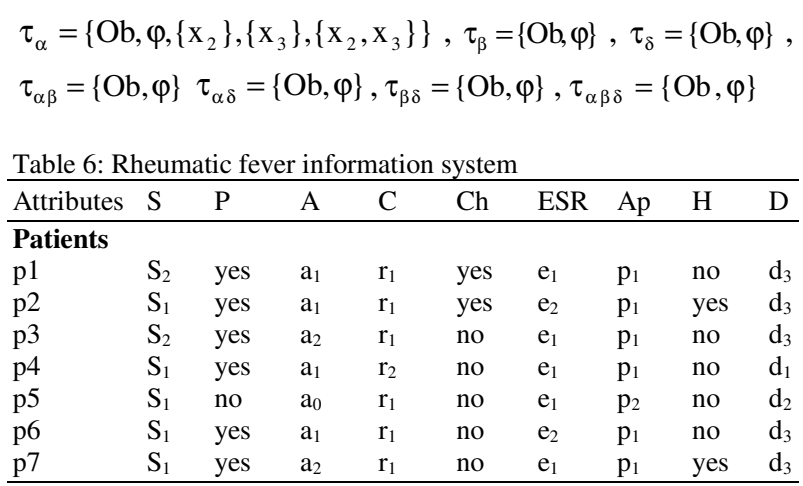


Table 7: Convert table

\begin{tabular}{|c|c|c|c|}
\hline $\begin{array}{l}\text { Attribute } \\
\text { symbol }\end{array}$ & Refers to? & $\begin{array}{l}\text { Attribute } \\
\text { values }\end{array}$ & Refers to? \\
\hline \multirow[t]{3}{*}{$\alpha$} & $\{\mathrm{S}, \mathrm{CH}\}$ & $\alpha_{1}$ & $\mathrm{~S}$ takes $\mathrm{s}_{1}$ \\
\hline & & $\alpha_{2}$ & $\mathrm{~K}$ takes $\mathrm{k}_{1}$ \\
\hline & & $\alpha_{3}$ & Each of $\{\mathrm{S}, \mathrm{K}\}$ takes $\left\{\mathrm{s}_{2}, \mathrm{k}_{2}\right\}$ \\
\hline \multirow[t]{5}{*}{$\beta$} & $\{\mathrm{P}, \mathrm{A}, \mathrm{ESR}\}$ & $\beta_{1}$ & $F$ takes $f_{1}$ \\
\hline & & $\beta_{2}$ & A takes $a_{1}$ \\
\hline & & $\beta_{3}$ & A takes $\mathrm{a}_{2}$ \\
\hline & & $\beta_{4}$ & E takes $e_{4}$ \\
\hline & & $\mathrm{B}_{5}$ & $\begin{array}{l}\text { Each of }\{F, A, E\} \text { takes } \\
\left\{f_{2,} a_{0}, e\right\}\end{array}$ \\
\hline \multirow[t]{4}{*}{$\delta$} & $\{\mathrm{C}, \mathrm{Ap}, \mathrm{H}\}$ & $\delta_{1}$ & $\mathrm{R}$ takes $\mathrm{r}_{1}$ \\
\hline & & $\delta_{2}$ & $\mathrm{P}$ takes $\mathrm{p}_{1}$ \\
\hline & & $\delta_{3}$ & $\mathrm{H}$ takes $\mathrm{h}_{3}$ \\
\hline & & $\delta_{4}$ & $\begin{array}{l}\text { Each of }\{\mathrm{R}, \mathrm{P}, \mathrm{H}\} \text { takes } \\
\left\{\mathrm{r}_{2}, \mathrm{p}_{2}, \mathrm{~h}_{2}\right\}\end{array}$ \\
\hline \multirow[t]{3}{*}{ D } & Diagnosis & $d_{1}$ & Rheumatic arthritis \\
\hline & & $\mathrm{d}_{2}$ & Rheumatic carditis \\
\hline & & $d_{3}$ & Rheumatic arthritis and carditis \\
\hline
\end{tabular}

Table 8: Multi-valued information system

\begin{tabular}{lllll}
\hline $\mathrm{U}$ & $\alpha$ & $\beta$ & $\delta$ & $\mathrm{D}$ \\
\hline $\mathrm{x}_{1}$ & $\left\{\alpha_{2}\right\}$ & $\left\{\beta_{1}, \beta_{2}, \beta_{3}\right\}$ & $\left\{\delta_{1}, \delta_{2}\right\}$ & $\left\{\mathrm{d}_{3}\right\}$ \\
$\mathrm{x}_{2}$ & $\left\{\alpha_{1}, \alpha_{2}\right\}$ & $\left\{\beta_{1}, \beta_{2}\right\}$ & $\left\{\delta_{1}, \delta_{2}, \delta_{3}\right\}$ & $\left\{\mathrm{d}_{3}\right\}$ \\
$\mathrm{x}_{3}$ & $\left\{\alpha_{3}\right\}$ & $\left\{\beta_{1}, \beta_{3}, \beta_{4}\right\}$ & $\left\{\delta_{1}, \delta_{2}\right\}$ & $\left\{\mathrm{d}_{3}\right\}$ \\
$\mathrm{x}_{4}$ & $\left\{\alpha_{1}\right\}$ & $\left\{\beta_{1}, \beta_{2}, \beta_{4}\right\}$ & $\left\{\delta_{2}\right\}$ & $\left\{\mathrm{d}_{1}\right\}$ \\
$\mathrm{x}_{5}$ & $\left\{\alpha_{1}\right\}$ & $\left\{\beta_{4}\right\}$ & $\left\{\delta_{1}\right\}$ & $\left\{\mathrm{d}_{2}\right\}$ \\
$\mathrm{x}_{6}$ & $\left\{\alpha_{1}\right\}$ & $\left\{\beta_{1}, \beta_{2}\right\}$ & $\left\{\delta_{1}, \delta_{2}\right\}$ & $\left\{\mathrm{d}_{3}\right\}$ \\
$\mathrm{x}_{7}$ & $\left\{\alpha_{1}\right\}$ & $\left\{\beta_{1}, \beta_{3}, \beta_{4}\right\}$ & $\left\{\delta_{1}, \delta_{2}, \delta_{3}\right\}$ & $\left\{\mathrm{d}_{3}\right\}$ \\
\hline
\end{tabular}

Now we will apply the relation $\mathrm{R}_{\mathrm{D}}=\{(\mathrm{x}, \mathrm{y}), \mathrm{f}(\mathrm{x}) \subseteq \mathrm{f}(\mathrm{y})\}$ to deal with the decision attribute $\mathrm{D}$ and we can construct the following topology:

$$
\begin{aligned}
& \tau_{\mathrm{D}}=\left\{\mathrm{Ob}, \varphi,\left\{\mathrm{x}_{1}, \mathrm{x}_{2}, \mathrm{x}_{3}, \mathrm{x}_{6}, \mathrm{x}_{7}\right\},\right. \\
& \left.\left\{\mathrm{x}_{1}, \mathrm{x}_{2}, \mathrm{x}_{3}, \mathrm{x}_{4}, \mathrm{x}_{6}, \mathrm{x}_{7}\right\},\left\{\mathrm{x}_{1}, \mathrm{x}_{2}, \mathrm{x}_{3}, \mathrm{x}_{5}, \mathrm{x}_{6}, \mathrm{x}_{7}\right\}\right\}
\end{aligned}
$$

We observe that, $\tau_{\alpha} \leq \tau_{\mathrm{D}}$, this leads to from the above contributions that $\{\alpha\}$ is the reduct and it is the core.

Then we can get the degree of dependency for each attribute as follows:

For $\mathrm{a}=\alpha$, we get $\gamma(\alpha, \mathrm{D})=\frac{2}{7}$, for $\mathrm{a}=\beta$, we get $\gamma(\beta, D)=0$ and for $\mathrm{a}=\delta, \gamma(\delta, \mathrm{D})=0$. But if we get the degree of dependencies for the other attributes we will find that:

$$
\begin{aligned}
& \gamma(\{\alpha, \beta\}, D)=\gamma(\{\alpha, \delta\}, D) \\
& =\gamma(\{\beta, \delta\}, D)=\gamma(C, D)=0
\end{aligned}
$$

Thus, the set of attributes of equal highest degree of dependency is the reduct of our system. So we conclude that $\{\alpha\}$ is the reduct of our data using the topological method also, $\{\alpha\}$ is the core of our system.

Now, we observe that the reduction that we got by using the GMIS is contained in the reduction that we got using the discernibility matrix and this clears for us that our method for getting the reduction is more precise than using the ROSETTA method. Because, the ROSETTA method can not apply on general binary relations.

Topological reduction of single valued datasets: By reduction we mean if we can remove some data from the data table given in our information system preserving its basic properties. To express this idea more precisely, let $\mathrm{S}=\left(\mathrm{Ob}, \mathrm{At},\left\{\mathrm{V}_{\mathrm{a}}: \mathrm{a} \in \mathrm{At}\right\}, \mathrm{f}_{\mathrm{a}}\right)$ be an information system (numerical system ). Let $r$ be a positive real, for each object $\mathrm{x} \in \mathrm{Ob}$ and for $\mathrm{a} \in \mathrm{At}$, $\mathrm{N}_{\mathrm{a}}(\mathrm{x}, \mathrm{r})$ is the a-neighborhood of $\mathrm{x}$ and defined by:

$$
\mathrm{N}_{\mathrm{a}}(\mathrm{x}, \mathrm{r})=\left\{\mathrm{y} \in \mathrm{Ob}:\left|\mathrm{f}_{\mathrm{a}}(\mathrm{x})-\mathrm{f}_{\mathrm{a}}(\mathrm{y})\right| \leq \mathrm{r}\right\}
$$

For any subset $\mathrm{B}$ of At, the B- neighborhood of $\mathrm{x}$ is defined by:

$$
\mathrm{N}_{\mathrm{B}}(\mathrm{x}, \mathrm{r})=\left\{\mathrm{y} \in \mathrm{Ob}:\left|\mathrm{f}_{\mathrm{a}}(\mathrm{x})-\mathrm{f}_{\mathrm{a}}(\mathrm{y})\right| \leq \mathrm{r} \quad \forall \mathrm{a} \in \mathrm{B}\right\}
$$

For any subset $\mathrm{X}$ of $\mathrm{Ob}$, we define two mappings Int, $\mathrm{Cl}: \mathrm{P}(\mathrm{Ob}) \rightarrow \mathrm{P}(\mathrm{Ob})$ as follows:

$$
\begin{aligned}
& \operatorname{Int}_{\mathrm{B}}(\mathrm{X})=\left\{\mathrm{x} \in \mathrm{Ob}: \mathrm{N}_{\mathrm{a}}(\mathrm{x}, \mathrm{r}) \subseteq \mathrm{X}, \forall \mathrm{a} \in \mathrm{B}\right\}, \mathrm{s} \\
& \mathrm{Cl}_{\mathrm{B}}(\mathrm{X})=\left\{\mathrm{x} \in \mathrm{Ob}: \mathrm{N}_{\mathrm{a}}(\mathrm{x}, \mathrm{r}) \cap \mathrm{X} \neq \phi, \forall \mathrm{a} \in \mathrm{B}\right\}
\end{aligned}
$$

The classes $\quad\left\{\operatorname{Int}_{\mathrm{B}}(\mathrm{X}): \mathrm{X} \subseteq \mathrm{Ob}, \mathrm{B} \subseteq \mathrm{At}\right\}$, $\left\{\mathrm{Cl}_{\mathrm{B}}(\mathrm{X}): \mathrm{X} \quad \subseteq \mathrm{Ob}, \mathrm{B} \subseteq \mathrm{At}\right\} \quad$ and $\left\{\mathrm{N}_{\mathrm{B}}(\mathrm{x}, \mathrm{r}): \mathrm{x} \in \mathrm{Ob}, \mathrm{B} \subseteq \mathrm{At}\right\}$ are subbases of a topological spaces denoted $\tau_{\mathrm{I}}, \tau_{\mathrm{C}}$ and $\tau_{\mathrm{N}}$ respectively.

Now let At $=\left\{\mathrm{a}_{1}, \mathrm{a}_{2}, \ldots, \mathrm{a}_{\mathrm{n}}\right\}$ and let $\tau_{\mathrm{I}_{\mathrm{a}_{1}}}, \tau_{\mathrm{I}_{\mathrm{a}_{2}}}, \ldots$, $\tau_{\mathrm{I}_{\mathrm{a}_{\mathrm{n}}}}, \tau_{\mathrm{C}_{\mathrm{a}_{1}}}, \tau_{\mathrm{C}_{\mathrm{a}_{2}}}, \ldots, \tau_{\mathrm{C}_{\mathrm{a}_{\mathrm{n}}}}$ and $\tau_{\mathrm{N}_{\mathrm{a}_{1}}}, \tau_{\mathrm{N}_{\mathrm{a}_{2}}}, \ldots, \tau_{\mathrm{N}_{\mathrm{a}_{\mathrm{n}}}}$ be the topologies induced by the subbases $\left\{\operatorname{Int}_{\mathrm{a} 1}(\mathrm{X})\right.$ : $\subseteq$ $\mathrm{Ob}\},\left\{\operatorname{Int}_{\mathrm{a} 2}(\mathrm{X}): \subseteq \mathrm{Ob}\right\}, \ldots,\left\{\operatorname{Int}_{\mathrm{an}}(\mathrm{X}): \subseteq \mathrm{Ob}\right\},\left\{\mathrm{Cl}_{\mathrm{a} 1}(\mathrm{X}):\right.$ $\subseteq \mathrm{Ob}\},\left\{\mathrm{Cl}_{\mathrm{a} 2}(\mathrm{X}): \subseteq \mathrm{Ob}\right\}, \ldots,\left\{\mathrm{Cl}_{\mathrm{an}}(\mathrm{X}): \subseteq \mathrm{Ob}\right\}$ and $\left\{\mathrm{N}_{\mathrm{a} 1}\right.$ $(\mathrm{X}): \subseteq \mathrm{Ob}\},\left\{\mathrm{N}_{\mathrm{a} 2}(\mathrm{X}): \subseteq \mathrm{Ob}\right\}, \ldots,\left\{\mathrm{N}_{\mathrm{an}}(\mathrm{X}): \subseteq \mathrm{Ob}\right\}$, respectively. These topologies called interior, closure and neighborhood topologies respectively.

One of the two attributes $a_{i}, a_{j}, i \neq j$ is called interior-dispensable in At if $\tau_{\mathrm{I}_{\mathrm{a}_{\mathrm{i}}}}=\tau_{\mathrm{I}_{\mathrm{a}_{\mathrm{j}}}}$,otherwise, $\mathrm{a}_{\mathrm{i}}$ or $\mathrm{a}_{\mathrm{j}}$ is indispensable in At. Let $\tau_{1,2}, \tau_{1,3}, \ldots, \tau_{\mathrm{n}-1, \mathrm{n}}$ be the 
topologies induced by $\tau_{\mathrm{I}_{a_{1}}} \cup \tau_{\mathrm{I}_{\mathrm{a}_{2}}}, \tau_{\mathrm{I}_{\mathrm{a}_{1}}} \cup \tau_{\mathrm{I}_{\mathrm{a}_{3}}}, \ldots$, $\tau_{\mathrm{I}_{\mathrm{a}_{n-1}}} \cup \tau_{\mathrm{I}_{\mathrm{a}_{\mathrm{n}}}}$ if interior topologies are used (the same terminology used if closure topologies or neighborhood topologies is replaced).

\section{CONCLUSION}

There are many approaches for obtaining topologies by relations and we used some of them in data reduction. These approaches were generalizations to Pawlak approaches namely, we ignored the notion of equivalence relations. Also, these approaches open the way for other approximations if we use the general topological recent concepts such as pre-open sets or semi-open sets. Make use of this terminology to obtain the missing values in incomplete datasets will be a good future work $^{[1,4,5,6,16]}$. Implementing software for large data sets reduction using advanced programming languages will be also a good future work.

\section{REFERENCES}

1. Brtka, V., E. Stokic and B. Srdic, 2008. Automated extraction of decision rules for leptin dynamics-A rough sets approach. J. Biomed. Inform., 41: 667-674 DOI: 10.1016/j.jbi.2008.01.005

2. Davvaz, B., 2008. A short note on algebraic Trough sets. Inform. Sci., 178: 3247-3252. DOI: 10.1016/j.ins.2008.03.014

3. Degang, C., Y. Wenxia and L. Fachao, 2008. Measures of general fuzzy rough sets on a probabilistic space. Inform. Sci., 178: 3177-3187. DOI: 10.1016/j.ins.2008.03.020

4. Hu, Q., D. Yu, J. Liu and C. Wu, 2008. Neighborhood rough set based heterogeneous feature subset selection. Inform. Sci., 178: 3577-3594. DOI: $10.1016 /$ j.ins.2008.05.024

5. Li, T., Y. Leung and W. Zhang, 2008. Generalized fuzzy rough approximation operators based on fuzzy coverings. Int. J. Approx. Reason., 48: 836-856. DOI: 10.1016/j.ijar.2008.01.006
6. Liu, G., 2008. Axiomatic systems for rough sets and fuzzy rough sets. Int. J. Approx. Reason., 48: 857-867. DOI: 10.1016/j.ijar.2008.02.001

7. Fotea, V.L., 2008. The lower and upper approximations in a hypergroup. Inform. Sci., 178: 3605-3615. DOI: 10.1016/j.ins.2008.05.009

8. Mi, J., Y. Leung, H. Zhao and T. Feng, 2008. Generalized fuzzy rough sets determined by a triangular norm. Inform. Sci., 178: 3203-3213. DOI: 10.1016/j.ins.2008.03.013

9. Min, F., Q. Liu and C. Fang, 2008. Rough sets approach to symbolic value partition. Int. J. Approx. Reason., 49: 689-700. DOI: 10.1016/j.ijar.2008.07.002

10. Pattaraintakorn, P. and N. Cercone, 2008. A foundation of rough sets theoretical and computational hybrid intelligent system for survival analysis. Comput. Math. Appl., 56: 1699-1708. DOI: 10.1016/j.camwa.2008.04.030

11. Qiana, Y., J. Liang and C. Dang, 2008. Consistency measure, inclusion degree and fuzzy measure in decision tables. Fuzzy Sets Syst., 159: 2353-2377. DOI: 10.1016/j.fss.2007.12.016

12. Wang, X., J. Zhai and S. Lu, 2008. Induction of multiple fuzzy decision trees based on rough set technique. Inform. Sci., 178: 3188-3202. DOI: 10.1016/j.ins.2008.03.021

13. Yang, Y. and R.I. John, 2008. Generalizations of roughness bounds in rough set operations. Int. J. Approx. Reason., 48: 868-878. DOI: 10.1016/j.ijar.2008.02.002

14. Yao, Y. and Y. Zhao, 2008. Attribute reduction in decision-theoretic rough set models. Inform. Sci., 178: 3356-3373. DOI: 10.1016/j.ins.2008.05.010

15. Zhao, S.E. and C.C. Tsang, 2008. On fuzzy approximation operators in attribute reduction with fuzzy rough sets. Inform. Sci., 178: 3163-3176. DOI: 10.1016/j.ins.2008.03.022

16. Zhang, S., 2009. Mining class-bridge rules based on rough sets. Expert Syst. Appl., 36: 6453-6460. DOI: 10.1016/j.eswa.2008.07.044 